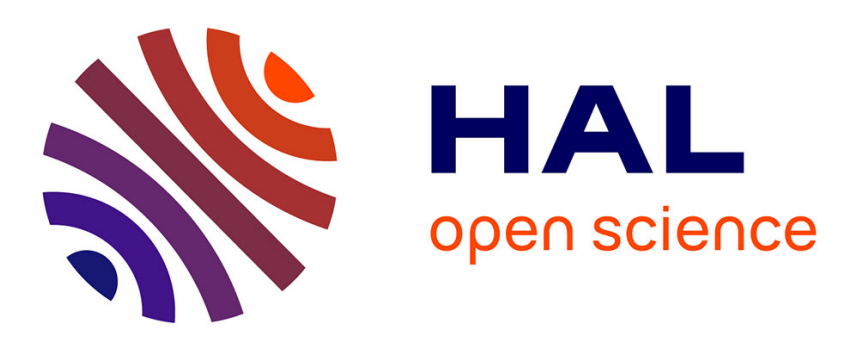

\title{
Src family tyrosine kinases-driven colon cancer cell invasion is induced by Csk membrane delocalization.
}

Audrey Sirvent, C. Bénistant, Julie Pannequin, L. Veracini, V. Simon, J.-F. Bourgaux, Frédéric Hollande, F. Cruzalegui, S. Roche

\section{- To cite this version:}

Audrey Sirvent, C. Bénistant, Julie Pannequin, L. Veracini, V. Simon, et al.. Src family tyrosine kinases-driven colon cancer cell invasion is induced by Csk membrane delocalization.. Oncogene, 2010, 29 (9), pp.1303-15. 10.1038/onc.2009.450 . hal-00443776

\section{HAL Id: hal-00443776 \\ https://hal.science/hal-00443776}

Submitted on 4 Jul 2010

HAL is a multi-disciplinary open access archive for the deposit and dissemination of scientific research documents, whether they are published or not. The documents may come from teaching and research institutions in France or abroad, or from public or private research centers.
L'archive ouverte pluridisciplinaire HAL, est destinée au dépôt et à la diffusion de documents scientifiques de niveau recherche, publiés ou non, émanant des établissements d'enseignement et de recherche français ou étrangers, des laboratoires publics ou privés. 
4,398 words

\section{Src family tyrosine kinases-driven colon cancer cell invasion is induced by Csk membrane delocalisation}

Audrey Sirvent ${ }^{1}$, Christine Bénistant ${ }^{1}$, Julie Pannequin ${ }^{2}$, Laurence Veracini ${ }^{1}$, Valérie Simon ${ }^{1}$, Jean-François Bourgaux ${ }^{3}$, Frédéric Hollande ${ }^{2}$, Francisco Cruzalegui ${ }^{4}$ \& Serge Roche ${ }^{1}$

${ }^{1}$ CNRS UMR5237, Equipe Labellisée « Ligue Nationale contre le Cancer », University of Montpellier 1 and 2, CRBM, 34000 Montpellier, France

${ }^{2}$ UMR 5203 INSERM U661, University of Montpellier 1 and 2, IGF, 34000 Montpellier, France.

${ }^{3}$ Service d’Hépato-Gastroentérologie, CHU Carémeau, Place du Pr. Robert Debré, 30029 Nimes, France.

${ }^{4}$ Division of Cancer Research and Drug Discovery, Institut de Recherches Servier, 125 chemin de Ronde, 78290 Croissy sur Seine, France

Correspondance: Serge Roche CRBM, UMR5237, 1919 route de Mende 34293 Montpellier Cedex 05, France.

Tel: +33467613373

Fax: 33467521559

e-mail: Serge.Roche@crbm.cnrs.fr

Running title: SFK deregulation in colon carcinoma cells

Keywords: Tyrosine kinase Src, oncogenic signalling, colorectal cancer, invasion, Csk 
Supplementary Figure 1

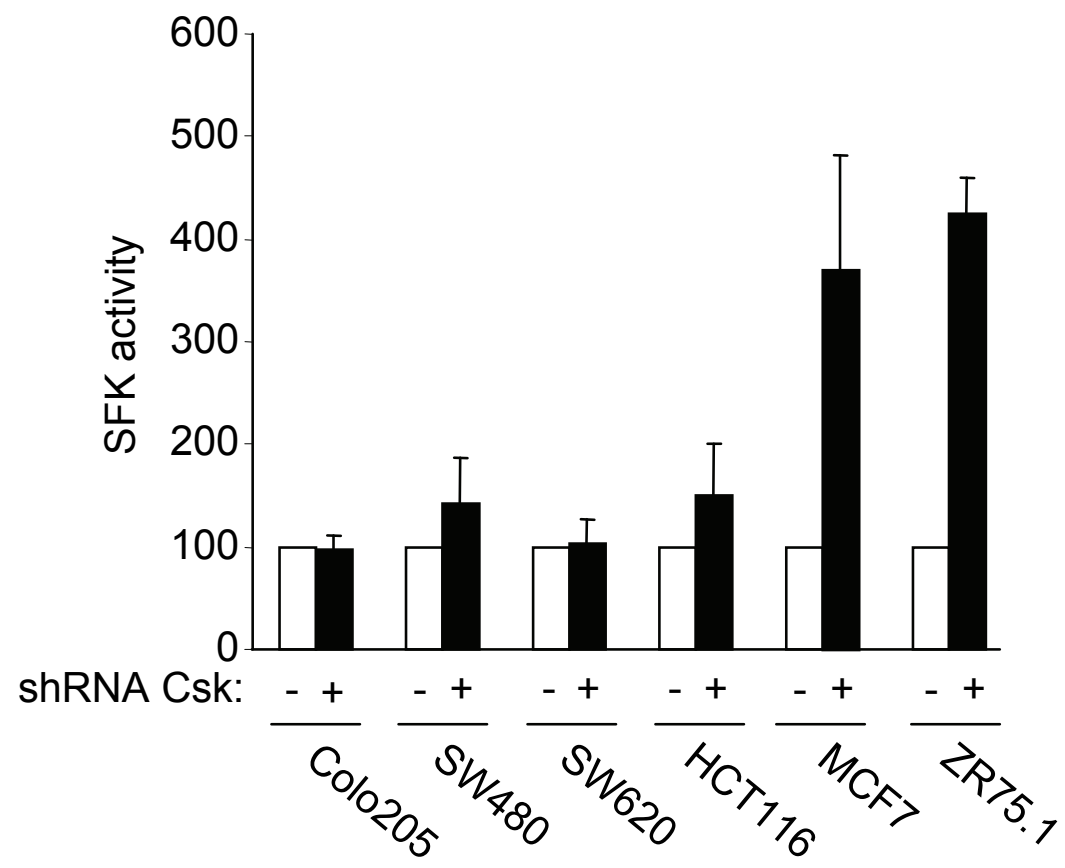

Supplementary Figure 1. The impact of Csk depletion on in vitro SFK activities.

Statistical analysis of kinase assays shown in Figure $2 b$. The mean \pm SD $(n>3)$ is shown 
a
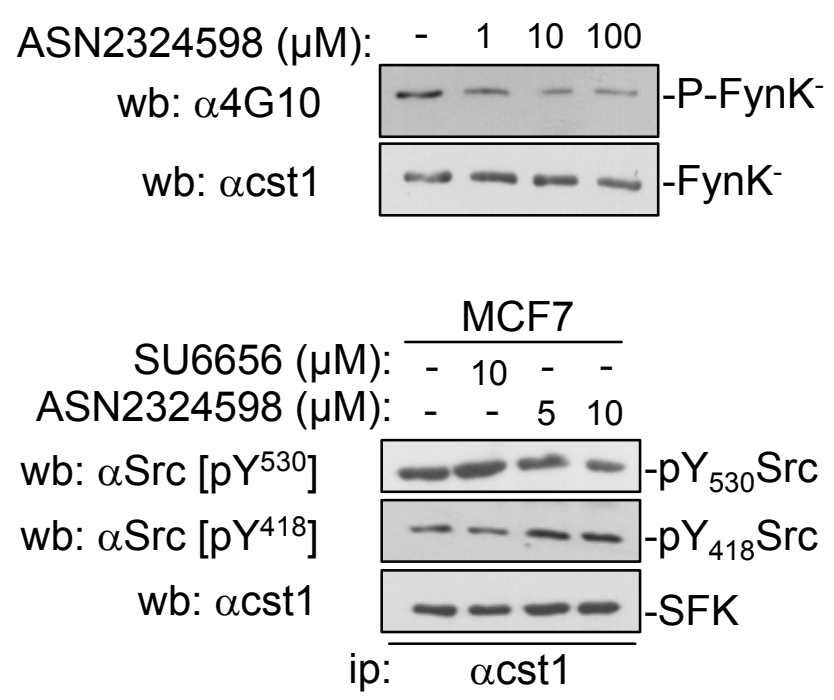

wb: atubulin
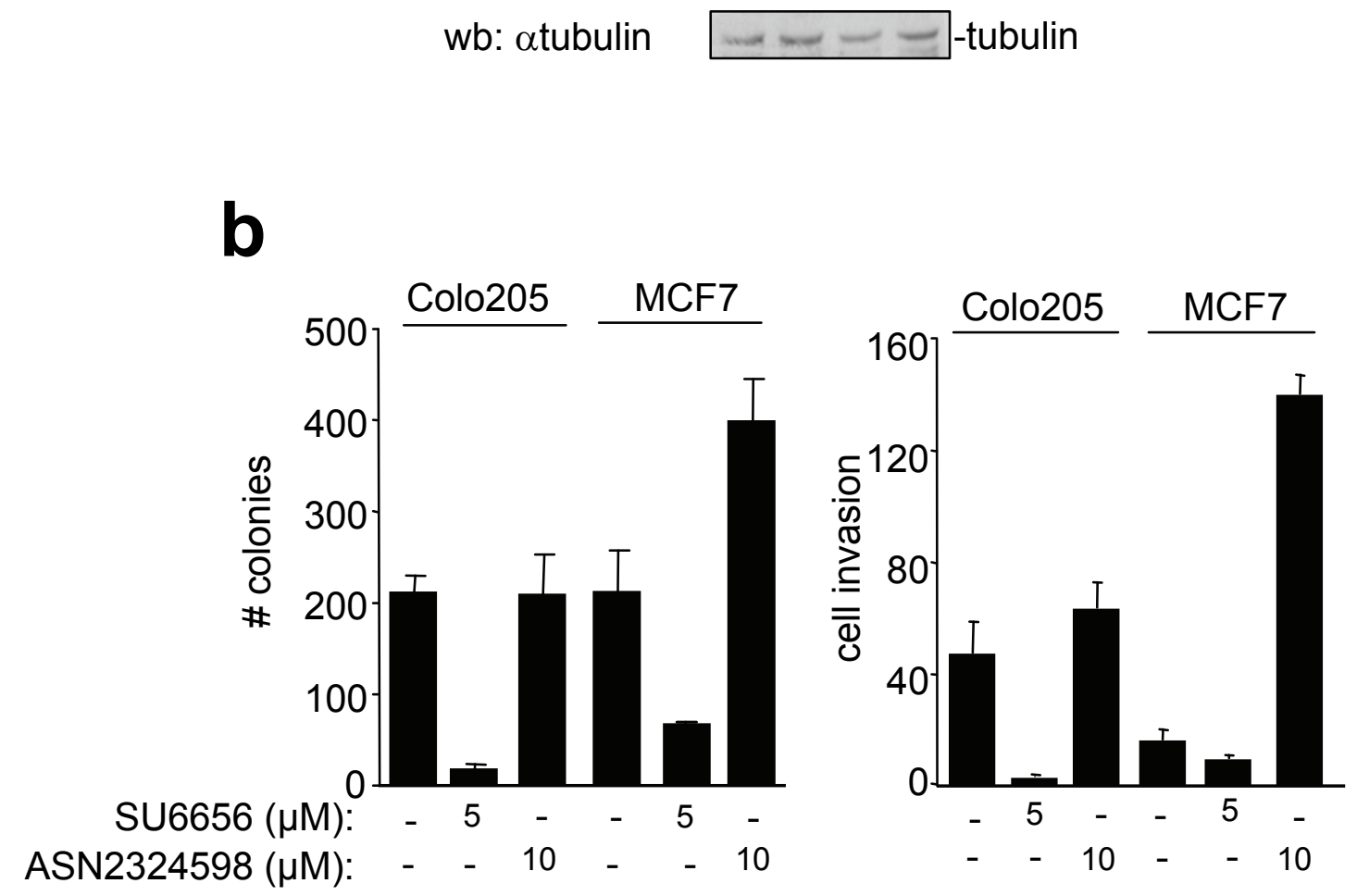
C
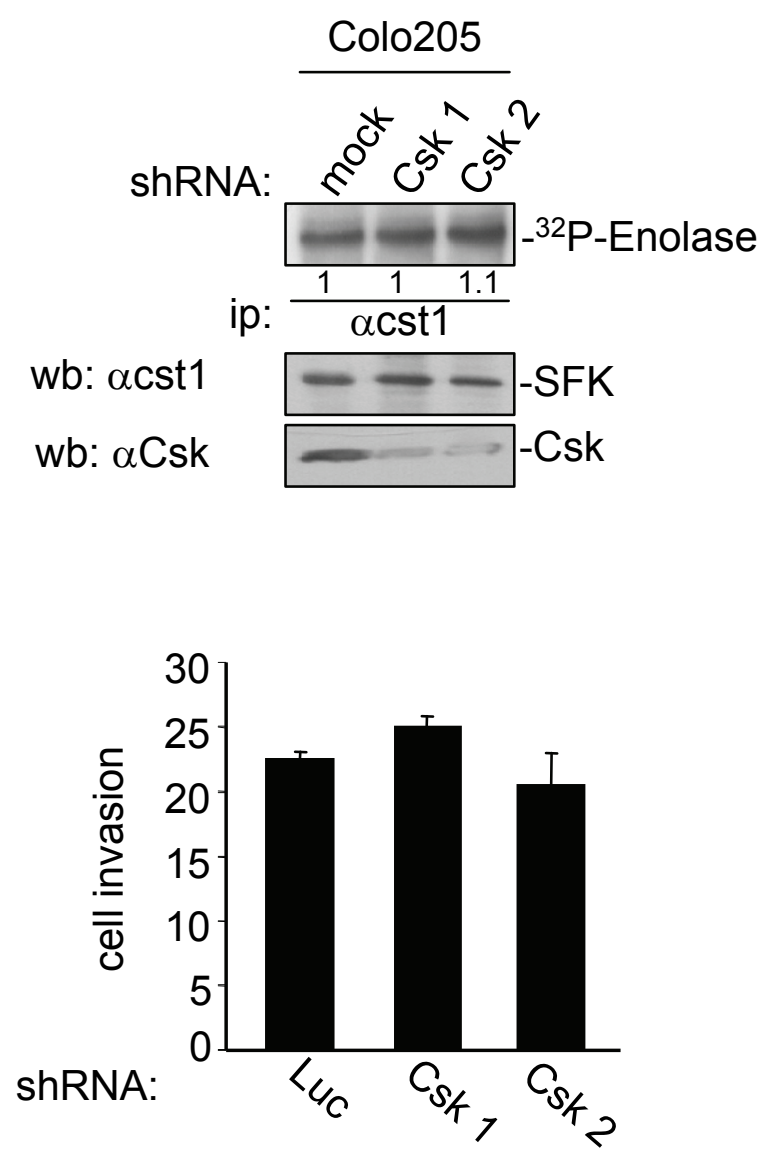

Supplementary Figure 2. Csk does not regulate SFK invasive activity in CRC cells.
(a), ASN2324598 inhibits Csk activity in vitro (upper panel) and in MCF7 cells (lower panel). (b), ASN2324598 potentiates growth in soft-agar (left) and invasion (right) of MCF7 cells. (c), Csk depletion does not affect SFK activity (upper panel) and cellular invasion of Colo205 cells (lower panel). 
a
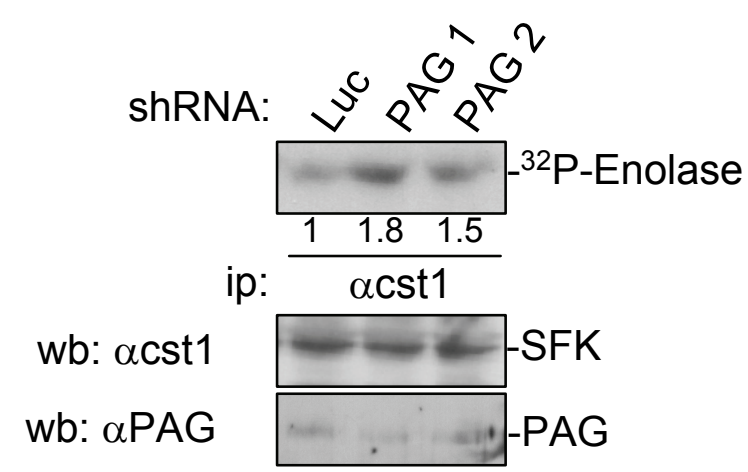

b

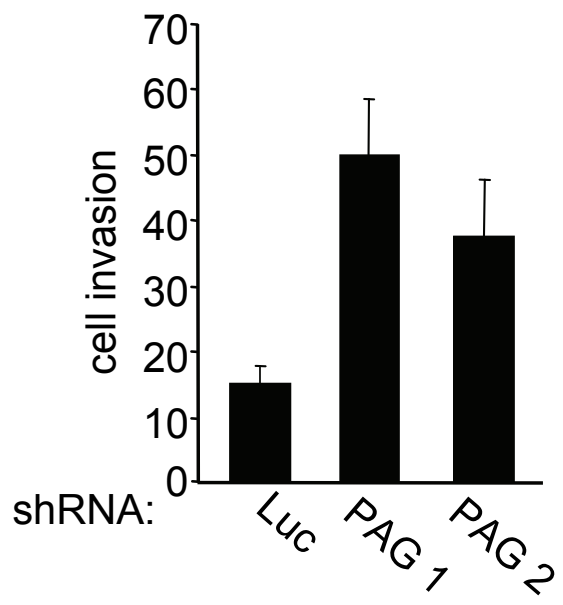

Supplementary Figure 3. PAG depletion in HCT116 cells increases SFK activity (a) and cellular invasion (b). 
Sirvent. Figure 1

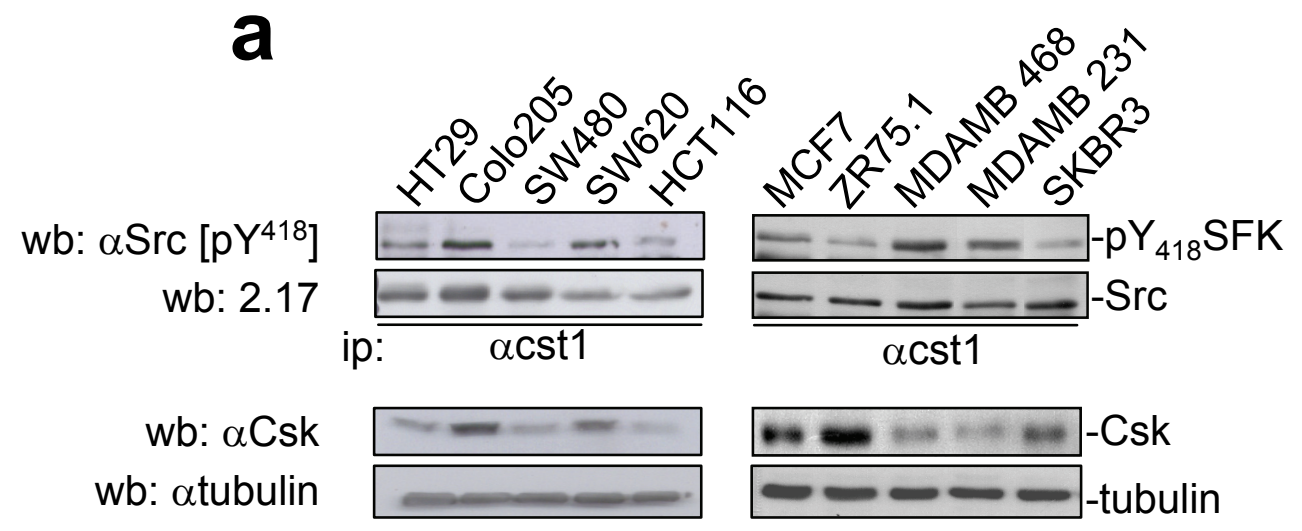

b

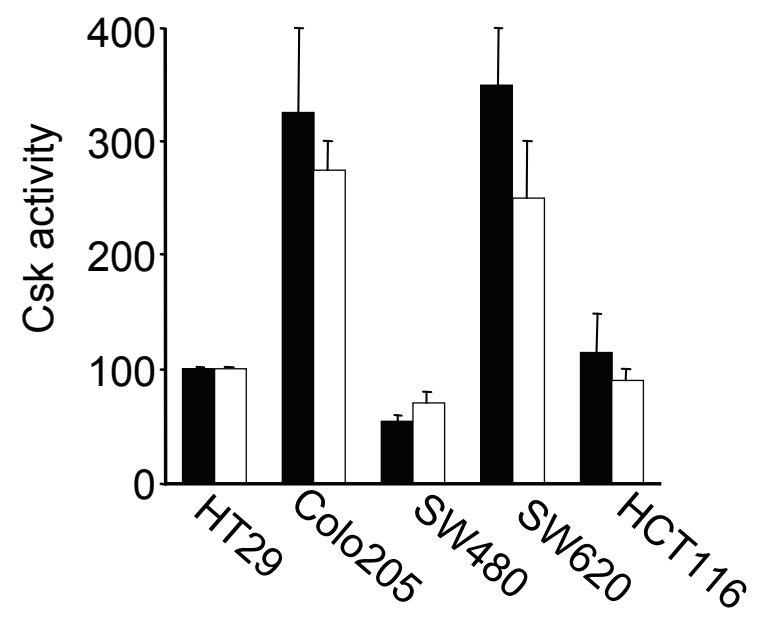

wb: $\alpha$ Csk wb: $\alpha \mathrm{cst} 1$ wb: $\alpha$ TR

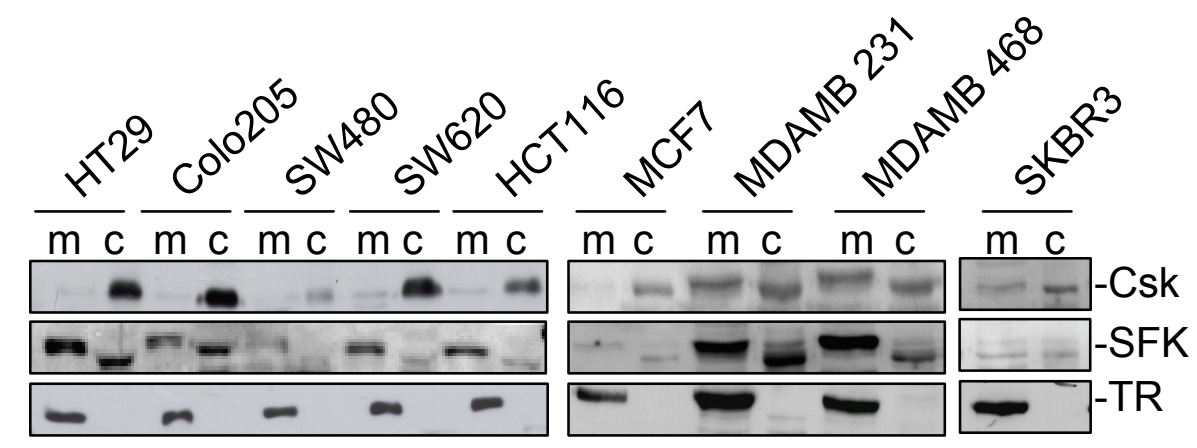


Sirvent. Figure 2

a

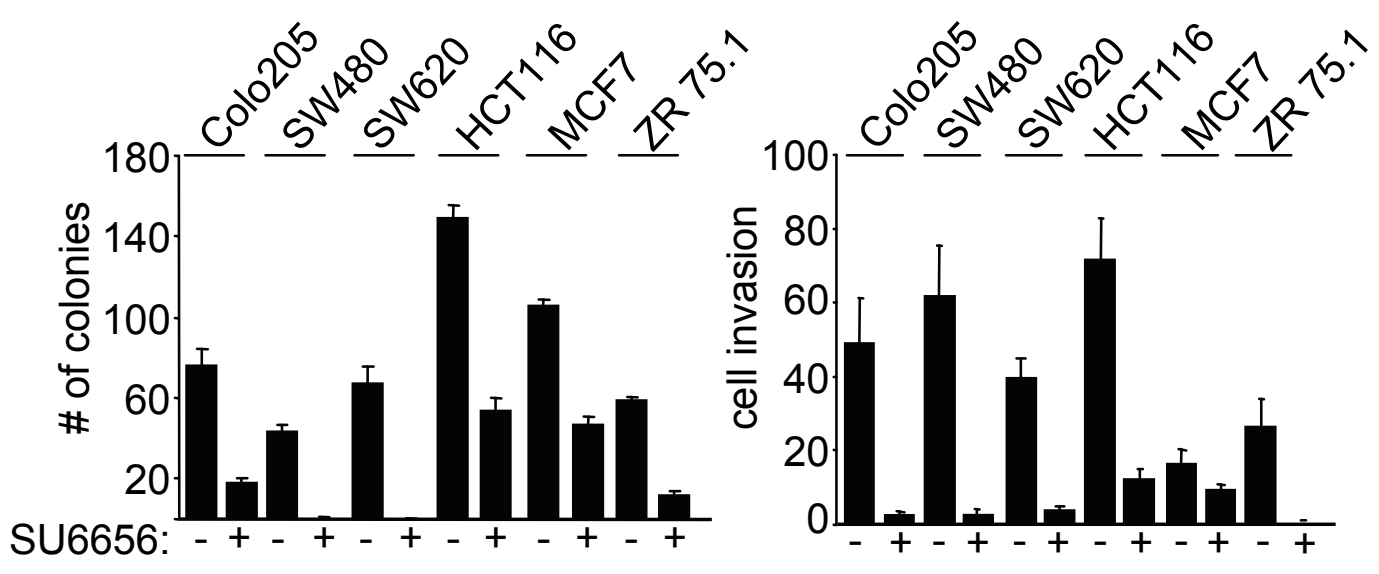

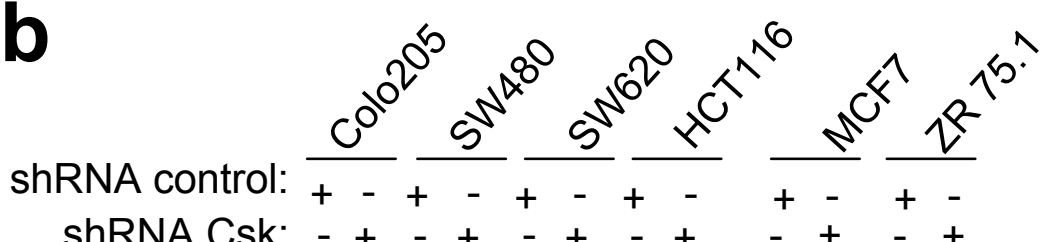
shRNA Csk: $-++++_{+}+-+++$

wb: $\alpha$ Csk

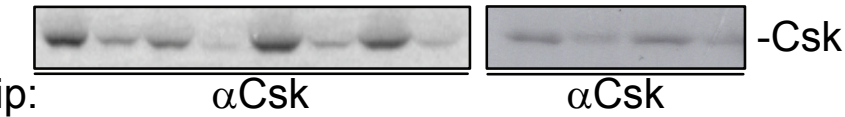

wb: atubulin

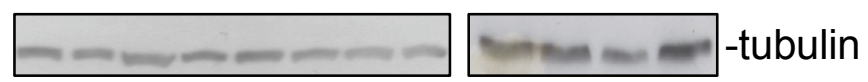

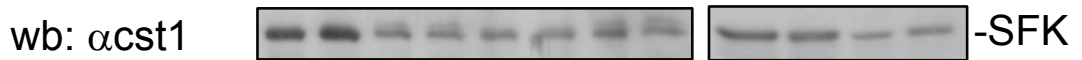

wb: $\alpha \operatorname{Src}\left[p Y^{418}\right]$
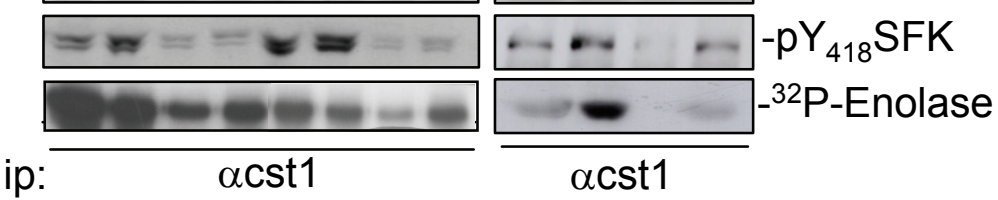

C

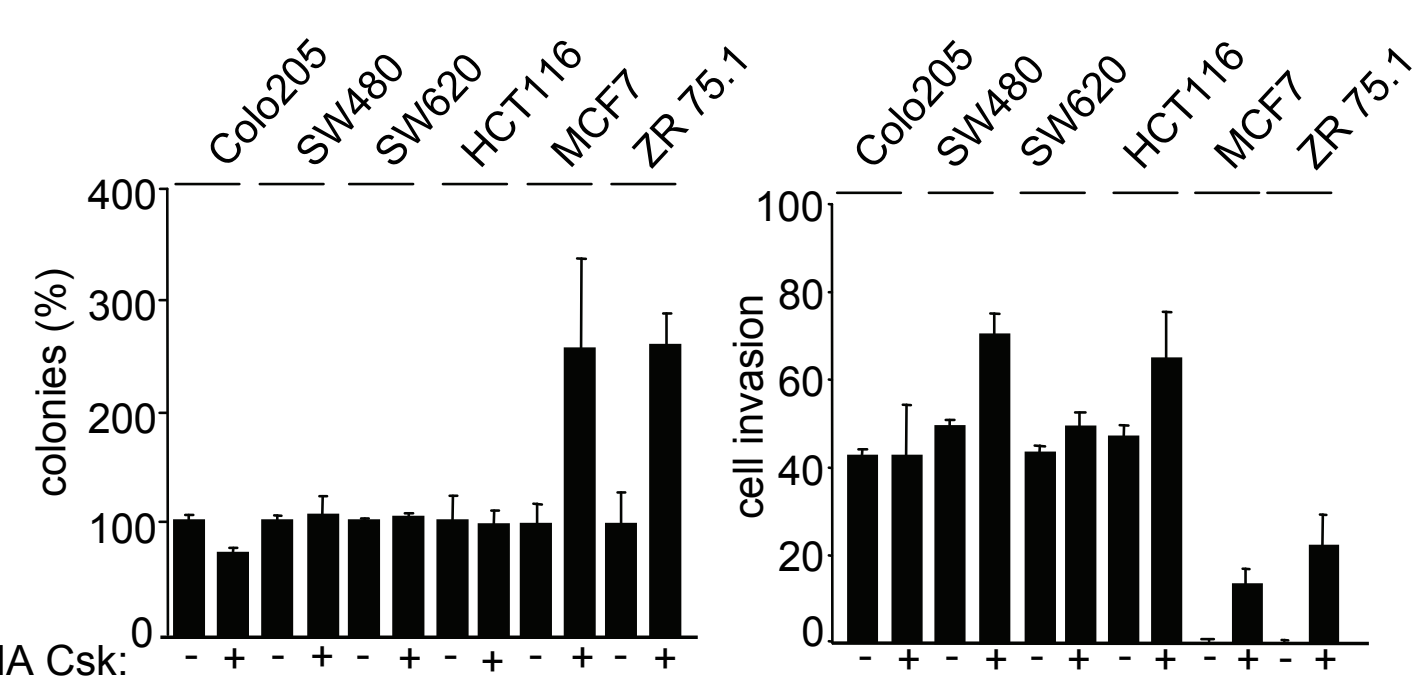

shRNA Csk: 
Sirvent. Figure 3

a

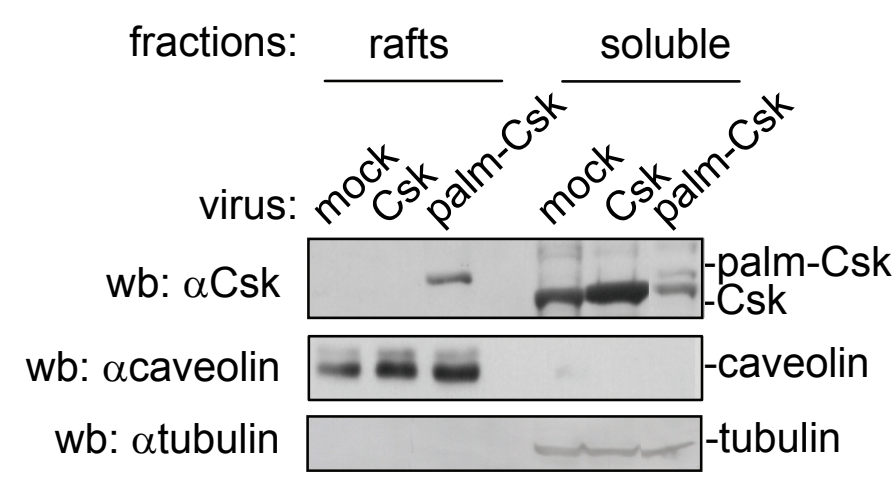

b

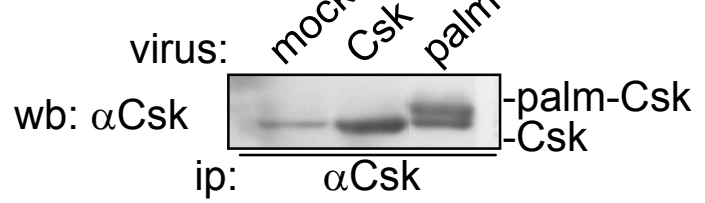

wb: $\alpha \operatorname{Src}\left[p Y^{418}\right] \quad-p Y_{418} S F K$

wb: $\alpha \operatorname{cst} 1$

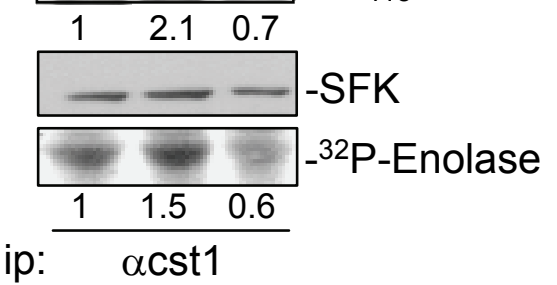

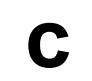

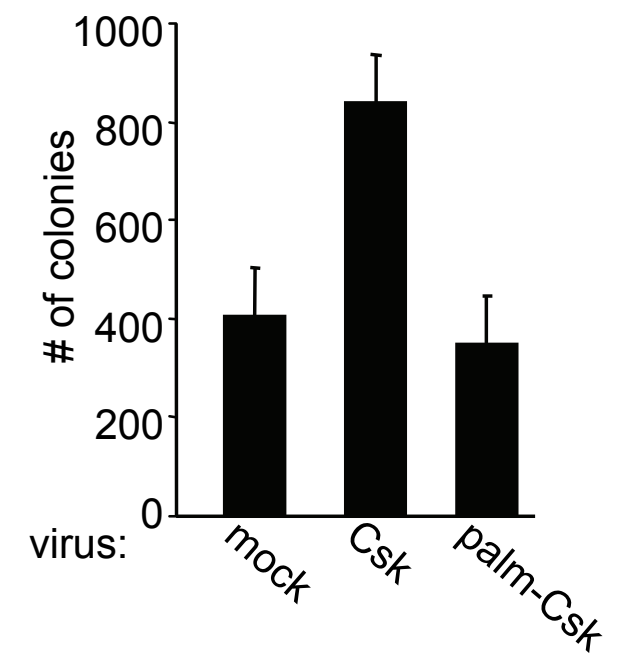

d

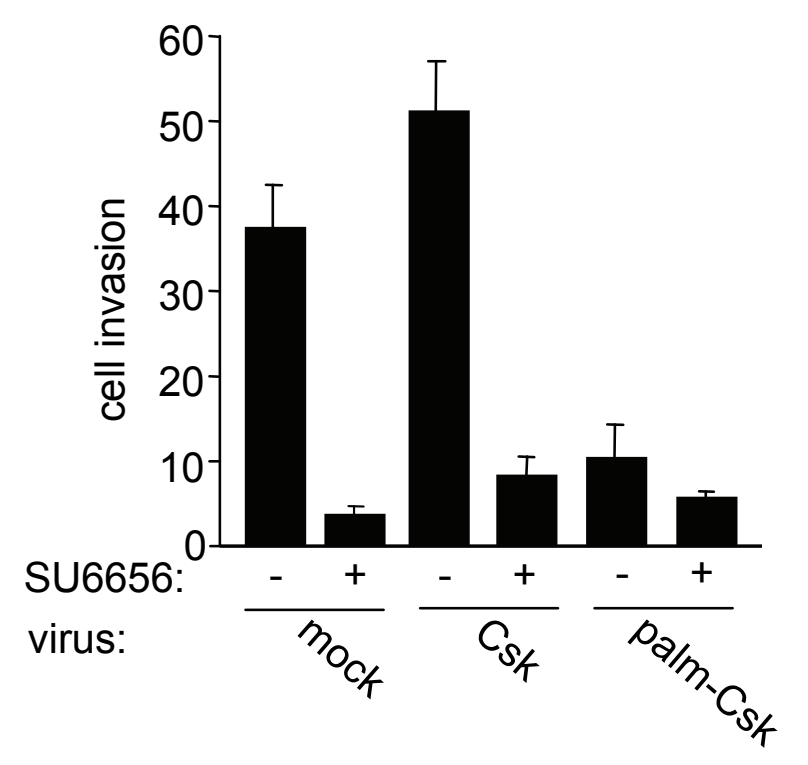


e

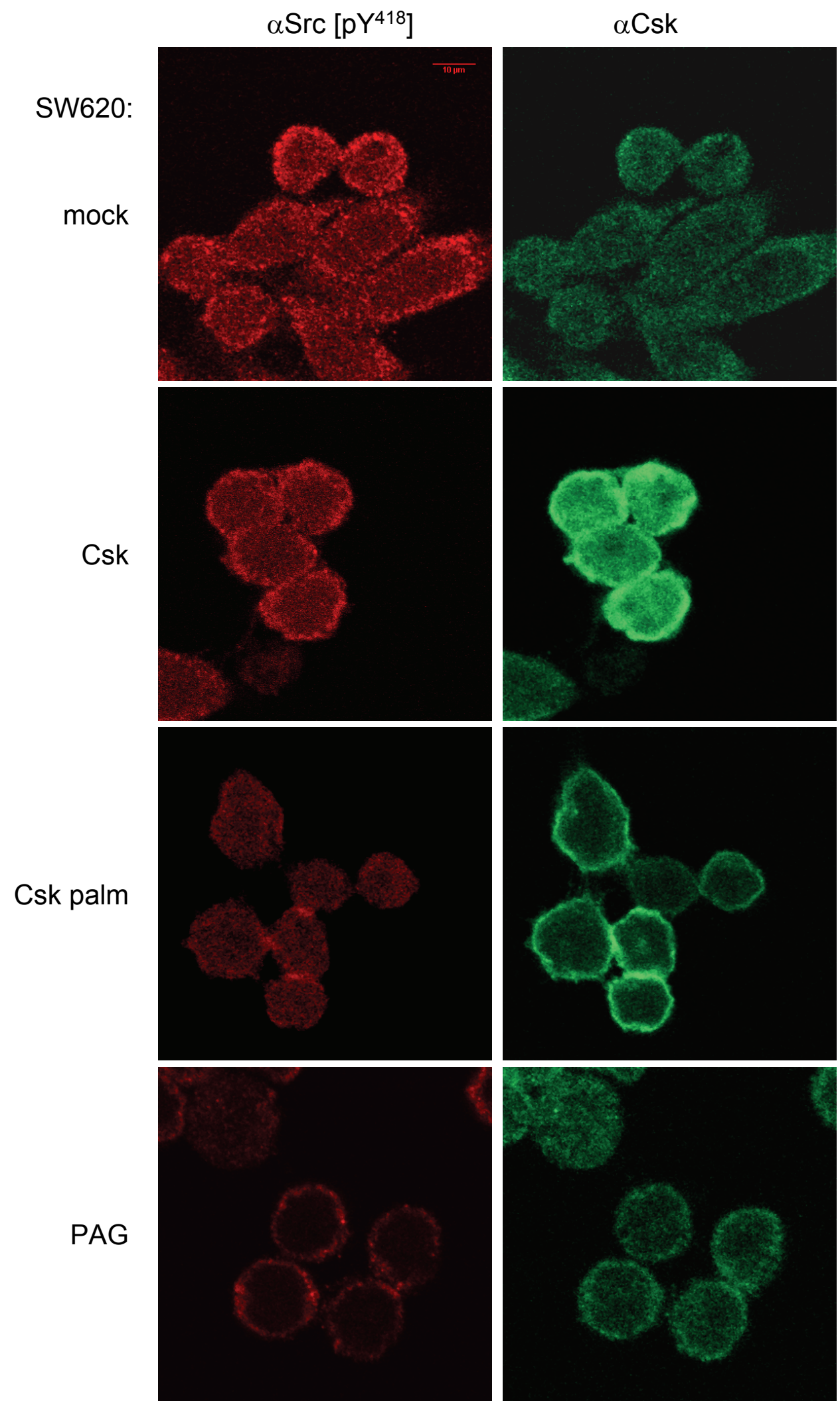


Sirvent. Figure 4

a

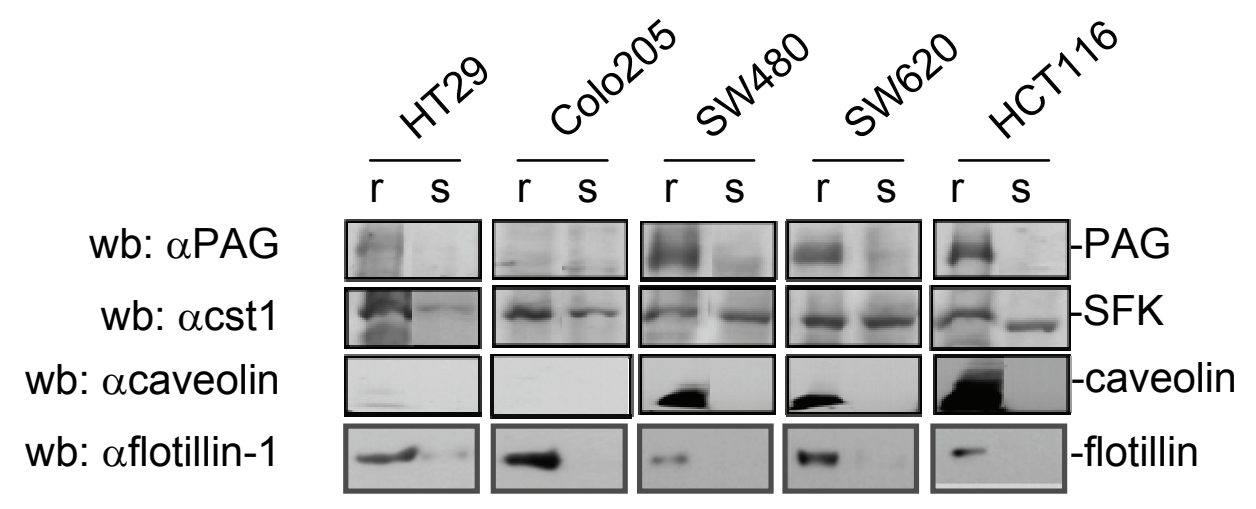

b

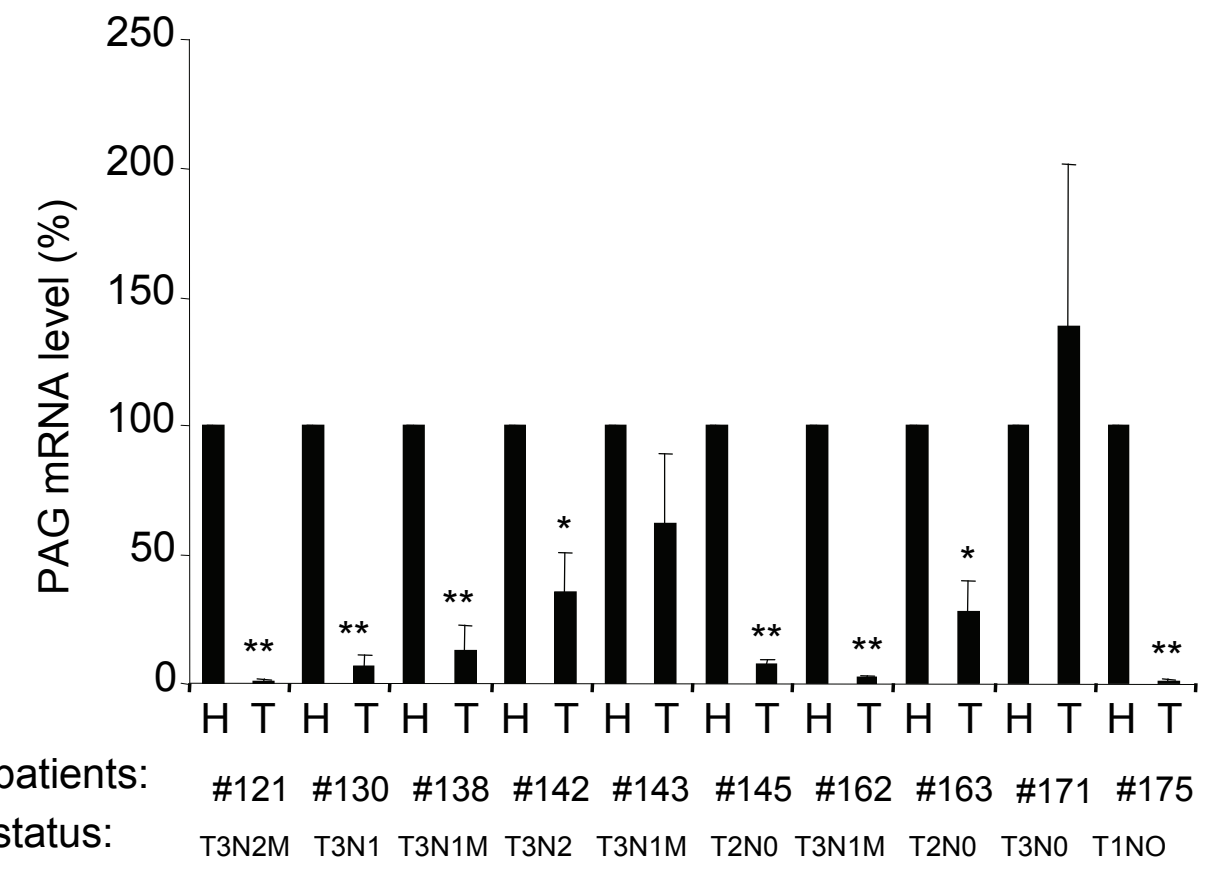




\section{C}
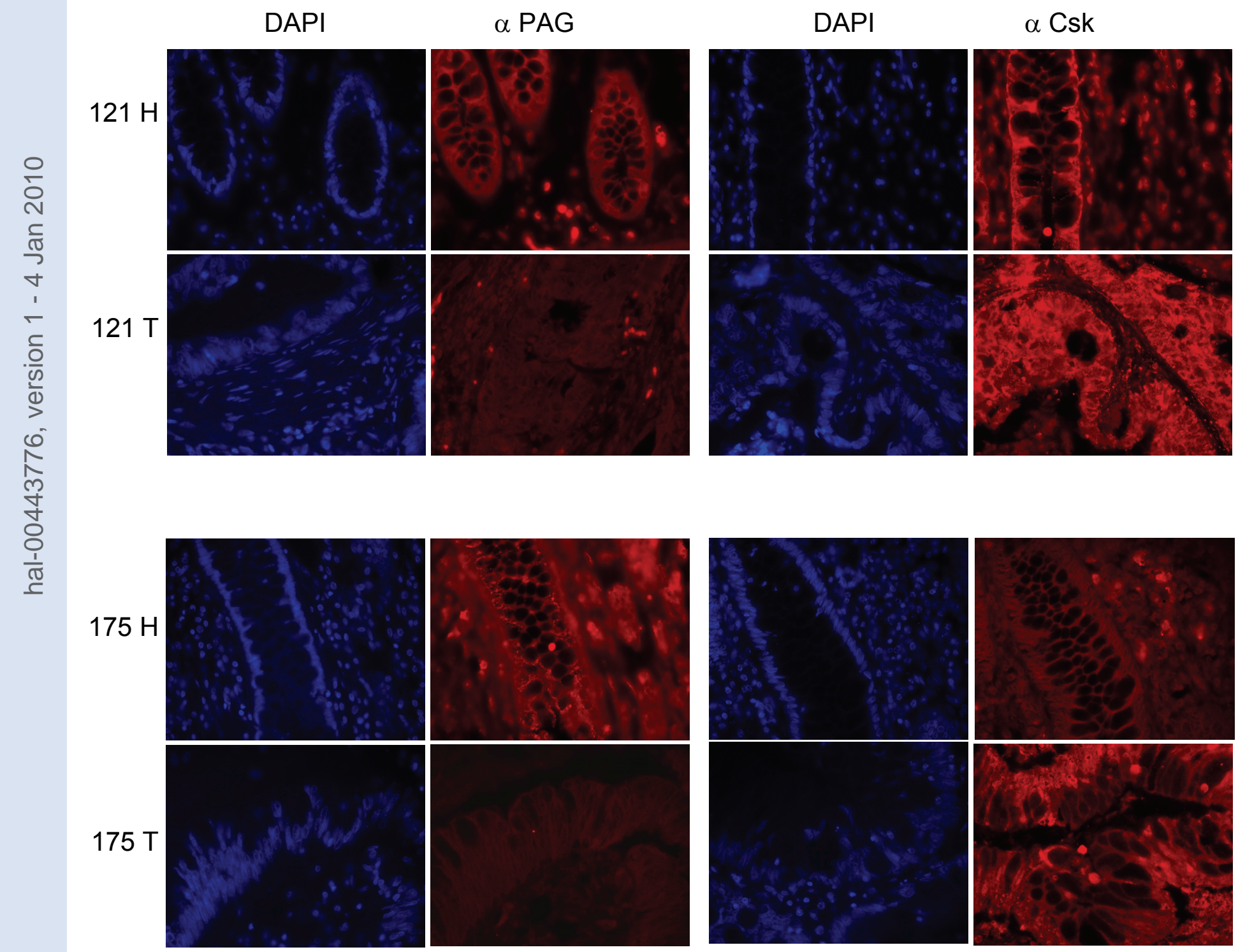


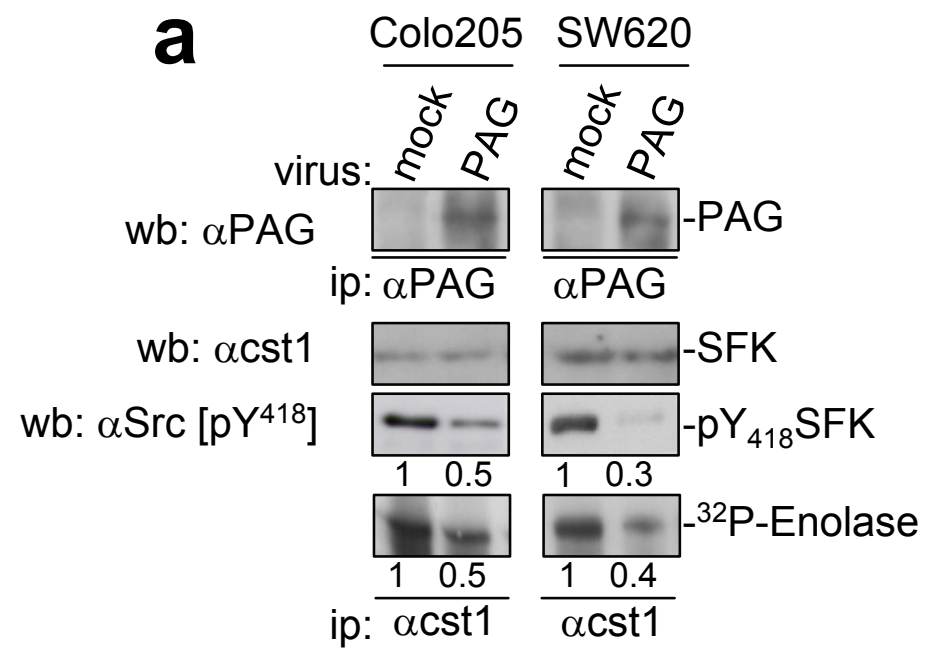

Sirvent. Figure 5
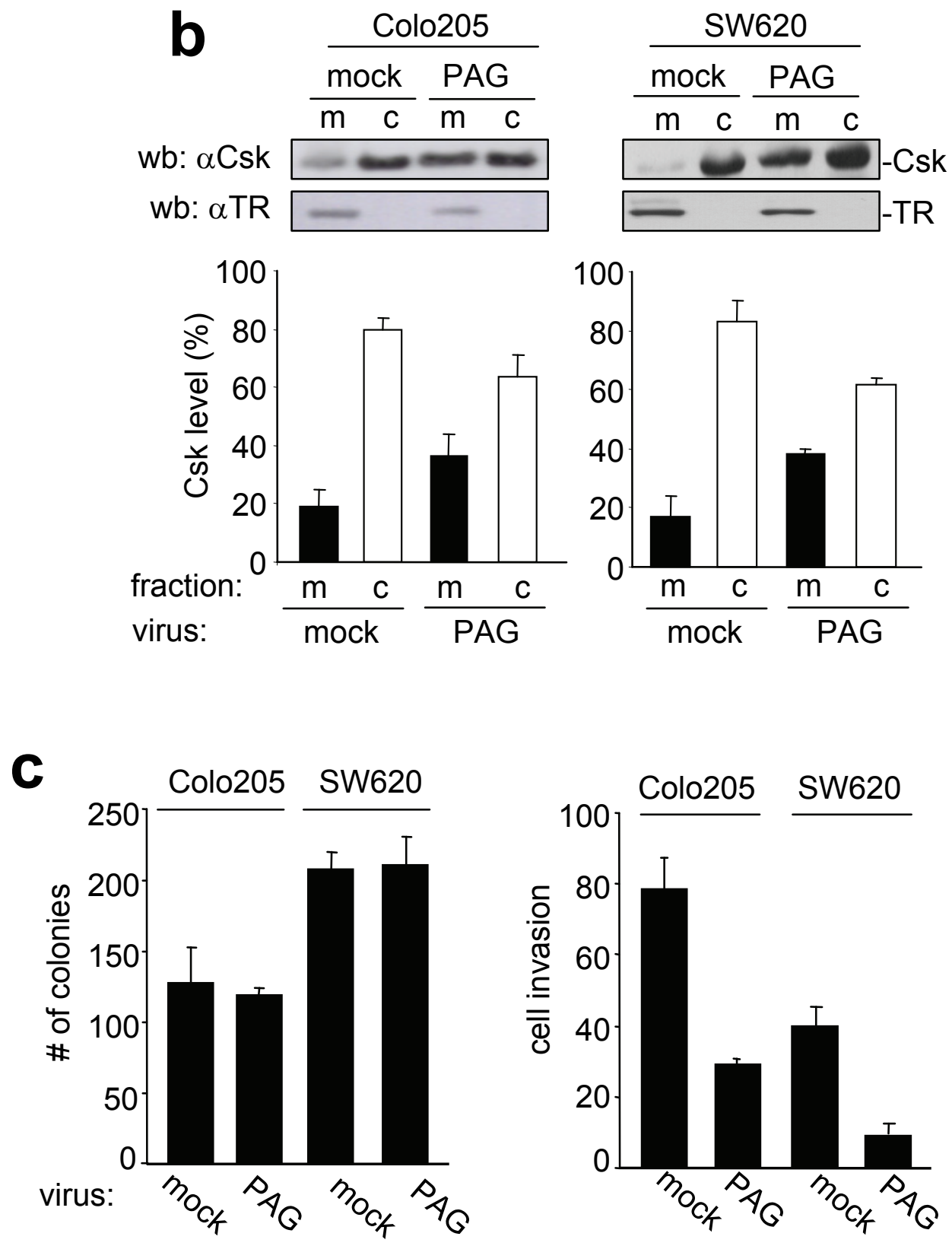


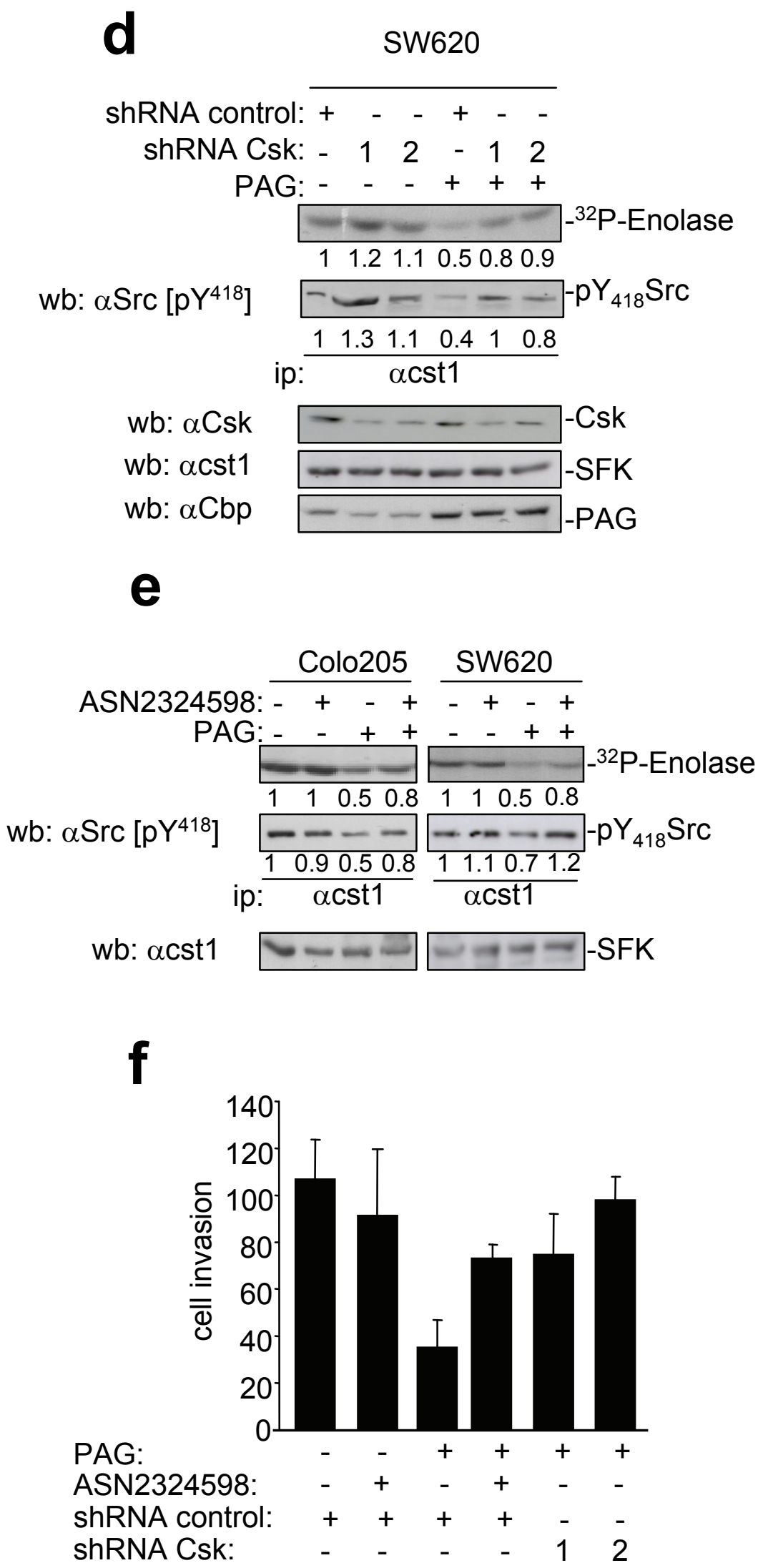




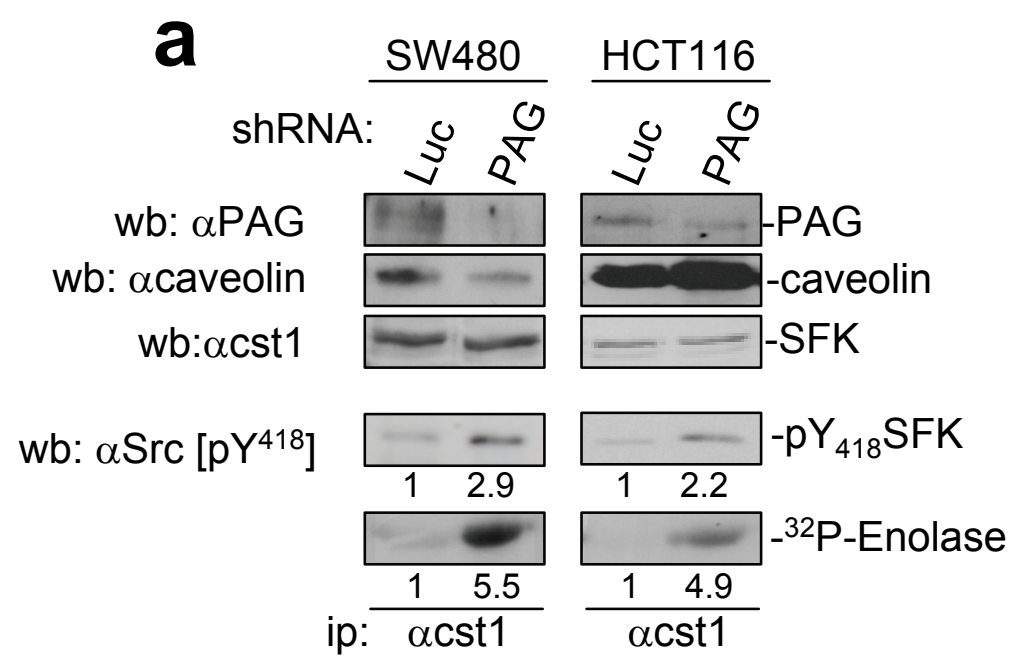

Sirvent. Figure 6
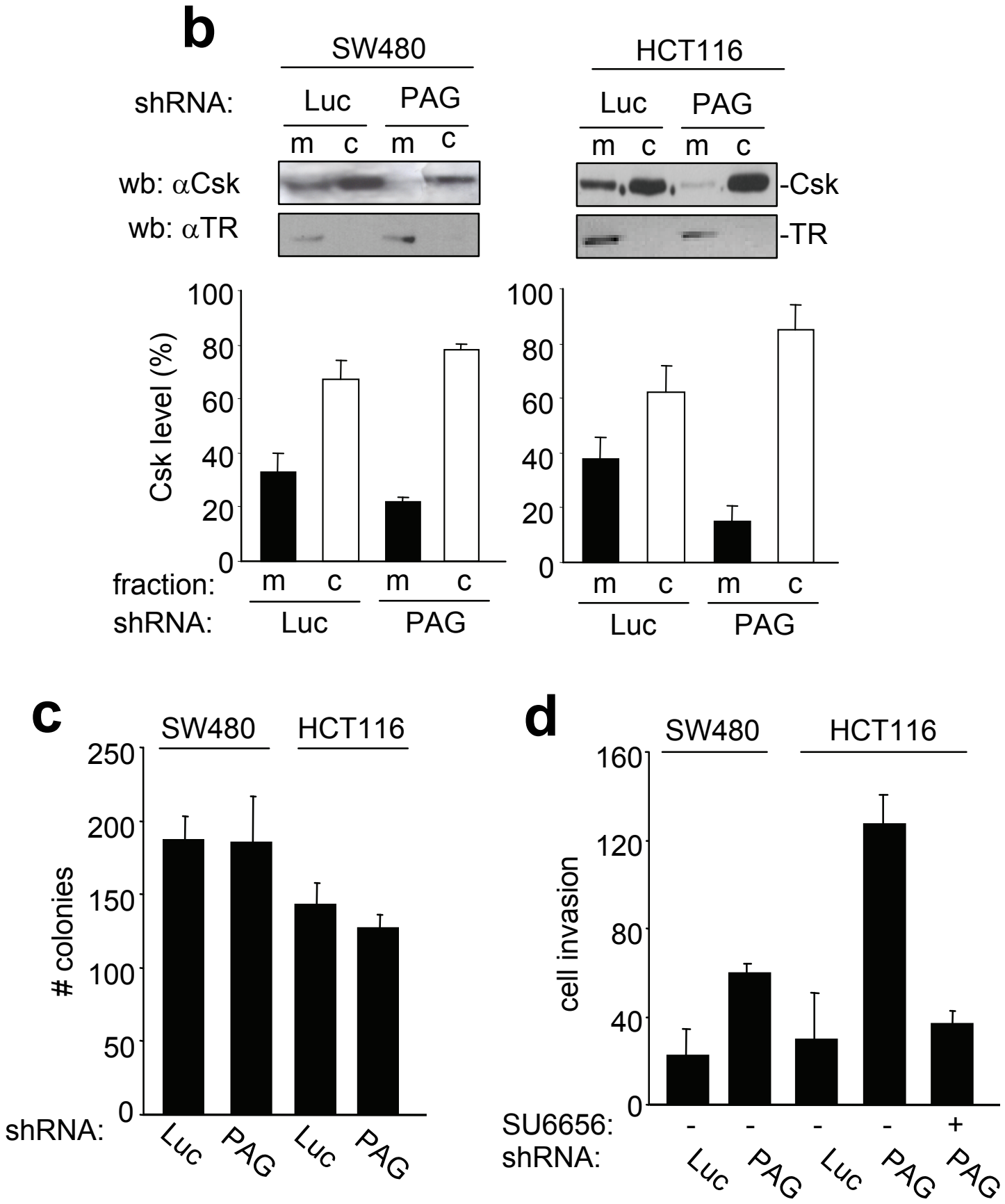


\section{ABSTRACT}

The non-receptor tyrosine kinases of the Src family (SFK) are frequently deregulated in human colorectal cancer (CRC) and they have been implicated in tumour growth and metastasis. How SFK are activated in this cancer has not been clearly established. Here we show that the SFK-dependent invasion is induced by inactivation of the negative regulator Cterminal Src kinase, Csk. While the level of Csk was inconsistent with SFK activity in colon cancer cells, its membrane translocation, needed for efficient regulation of membrane localised SFK activity, was impaired. Accordingly, Csk down-regulation did not affect SFK oncogenic activity in these cells, while expression of a membrane-localised form of this kinase affected their invasive activity. Down-regulation of the transmembrane and raftslocalised Csk-binding protein PAG was instrumental for the cytoplasmic accumulation of Csk. Re-expression of PAG in cells from late-stage CRC inhibited SFK invasive activity in a Csk-dependent manner. Conversely, inactivation of its residual expression in early-stage CRC cells promoted SFK invasive activity. Finally, this mechanism was specific to CRC as Csk coupling to SFK was readily detected in breast cancer cells. Therefore, Csk mis-localisation defines a novel mechanism for SFK oncogenic activation in CRC cells. 


\section{INTRODUCTION}

The non receptor tyrosine kinases of the Src family (SFK) play important roles in cell growth and migration induced by extracellular stimuli, including growth factors and integrins (Thomas and Brugge, 1997). They also show oncogenic activity when deregulated, a situation originally found with v-Src, the transforming product of the avian retrovirus RSV (Yeatman, 2004). Since then, SFK have been reported as deregulated in a large variety of human cancers (Summy and Gallick, 2003). Remarkably, kinase activities of Src and Yes are frequently elevated in CRC as compared to the normal counterpart and this has been associated with a poor clinical outcome (Summy and Gallick, 2003). Since then, they have been implicated in colon tumour progression and metastasis (Summy and Gallick, 2003). For example, Src regulates growth, survival and invasion of CRC cells in vitro (Emaduddin et al., 2008; Summy and Gallick, 2003) and contributes to tumour growth, angiogenesis and metastasis in mouse xenografts (Summy and Gallick, 2003). The function of Yes in CRC is less clear, although a role in cellular invasion has been proposed for this protein (Summy and Gallick, 2003). Based on these observations, SFK have become attractive therapeutic targets in advanced CRC and several small inhibitors are under clinical trials.

How SFK are deregulated in colon cancer is an important issue that has not been thoroughly addressed. In contrast to Ras, Src activation by mutation is a rare event, suggesting the existence of alternative mechanisms for oncogenesis (Irby et al., 1999). Kinase activation often correlates with protein overexpression (Yeatman, 2004), but overexpression alone in a normal cellular context is not sufficient to induce cell transformation, as SFK are subjected to strict regulation that maintain the enzymes in an inactive form. Precisely, this relies on intramolecular interactions of the SH2 domain with pTyr529 (referring to human Src) and the SH3 domain within a linker domain between the SH2 and the catalytic core, thus keeping the kinase in a closed and inactive conformation (Boggon and Eck, 2004). Phosphorylation of 
Tyr529 is therefore crucial for Src inactivation. Accordingly, mutation of this residue into Phe leads to oncogenic activity and deletion of this residue is observed in all retroviral SFK alleles, which largely contributes to their transforming activity. Since SFK mutation is highly infrequent in human cancer, it has been postulated that oncogenic activation implicates the alteration of SFK regulators, all of which have yet to be identified (Yeatman, 2004). In this context, several candidates have been suggested to disrupt the SH2-pTyr529 intramolecular interaction. These include growth factor receptors, via their association with SFK-SH2 (Mao et al., 1997) and tyrosine phosphatases that dephosphorylate pTyr529 (Liang et al., 2007; Zheng et al., 2008; Zhu et al., 2007). While probably activated in a subset of tumours, they may not account for the kinase deregulation observed in CRC.

An additional possible mechanism for deregulation of SFK activity involves the functional alteration of the kinase activity responsible for Tyr529 phosphorylation, the cytoplasmic tyrosine kinase Csk. The potential importance of this mechanism has been highlighted by the phenotypic consequences of Csk gene inactivation in mice leading to aberrant SFK activity and lethality during embryogenesis (Imamoto and Soriano, 1993; Nada et al., 1993). Similarly, loss of $d C s k$ in drosophila can lead to overproliferation and disorganization of tissue architecture (Read et al., 2004; Stewart et al., 2003). Nevertheless, the involvement of Csk in CRC remains controversial. Indeed Csk level was found either down-regulated or up-regulated in CRC tumours (Bénistant et al., 2001; Cam et al., 2001; Zhu et al., 2008), inconsistent with a potential tumour suppressor function. This notion is reinforced by the detection of Csk auto-antibodies in some patients with CRC, indicating that this tyrosine kinase is a novel tumour antigen in this cancer (Bénistant et al., 2001). Interestingly, while SFK are very good substrates in vitro they do not interact efficiently with Csk in vivo. This is due to the fact that while SFK are present at the membranes, inactive Csk is strictly cytosolic. Thus, in vivo activity additionally requires membrane-associated Csk- 
binders that allow its recruitment to sub-cellular compartments where SFK reside. For example, the cytoskeletal-associated protein paxillin recruits Csk to the focal adhesion sites to the regulation of cell migration (Schaller and Parsons, 1995), while the signalling protein Dok-1 induces Csk translocation to the plasma membrane for mitogenic regulation (Zhao et al., 2006). Additional Csk-binders have been identified including the structural protein of caveolae, caveolin-1 (Lee et al., 2000), the junctional proteins VE-cadherin (Baumeister et al., 2005) and ZO-1 (Saito et al., 2008) and the transmembrane protein PAG/Cbp (Brdicka et al., 2000; Kawabuchi et al., 2000) localised in cholesterol-enriched membrane domains or rafts (named PAG in this study). Interestingly, SFK phosphorylation of these proteins triggers their binding to Csk via a SH2-pTyr dependent mechanism, which creates a negative feedback regulatory loop. Yet, the status of these proteins in CRC is largely unknown. Here we show that Csk mis-localisation defines an important and novel mechanism for SFK oncogenic activation in CRC. Moreover, we have identified the PAG transmembrane protein as one of Csk-binding protein involved in this molecular process, resulting in the induction of SFK invasive activity.

\section{RESULTS}

\section{Csk membrane localisation is reduced in CRC cells.}

We first analysed Csk activity in CRC cells. As shown in Figure 1a (left panel), Csk level was higher in cell-lines from CRC metastases (SW620 and Colo205) as compared to those which originated from primary tumours (SW480, HCT116 and HT29). Moreover, Csk levels positively correlated with Src activity in agreement with the situation observed in CRC tumour biopsies (Bénistant et al., 2001). In contrast, Csk levels inversely correlated with SFK activities in breast cancer cells of various sub-types [Estrogen Receptor(ER)+, HER2+ and triple negative for ER, progesterone receptor and HER2] (Figure 1a, right panel), suggesting 
that Csk is still coupled to SFK activities in this cancer. We thus hypothesised that Csk could be inactive in colorectal tumours and we analysed Csk catalytic activity in CRC cells. To this end, Csk was immunoprecipitated from cancer cell-lysates and its in vitro kinase activity was measured using polyGlu-Tyr as a substrate. A higher kinase activity was obtained from CRC cell lines from more advanced, aggressive cancer, which tightly correlated with its expression level (Figure 1b). Indeed, Specific activities were of 0.7-1.4 range, indicating that Csk was not significantly altered in CRC cells. Similar results were obtained using the kinase inactive FynK298M as a specific substrate (Koegl et al., 1994)(specific activity of 0.9-1.15 range), indicating that its substrate specificity was not modified either. We next measured Csk subcellular localisation by cell fractionation (Figure 1c, left panel). Surprisingly, Csk was predominantly found in cytosolic fractions unlike SFK, which were largely localised at the membranes. In contrast, Csk was equally partitioned in membranes and cytosolic fractions of breast cancer cells (Figure 1c, right panels), indicating that its membrane localisation was specifically impaired in CRC cells.

\section{Csk inhibition does not affect SFK oncogenic activity in CRC cells.}

The function of Csk was next addressed in CRC cells. We first confirmed that the Csk substrates SFK play important roles in transforming properties of CRC cells; specifically anchorage-independent growth and invasion were inhibited by treatment with the SFK pharmacological inhibitor SU6656 (Figure 2a). Similar results were obtained in MCF7 and ZR75.1 ER ${ }^{+}$-breast cancer cells (Figure 2a), which is in agreement with an important role for SFK in ER oncogenic signalling (Ishizawar et al., 2004; Sirvent et al., 2007). In contrast, the SFK inhibitor had no effect on HER2+ breast cancer cells SKBR3 and BT474, indicating that SFK do not play a role in every breast cancer cells [(Sirvent et al., 2007) and not shown]. Due to the important function of SFK in CRC cells, we next investigated the role of Csk in CRC 
cells growth and invasion. To this end, Csk was inactivated using a shRNA approach that induces a $>70 \%$ reduction of its protein level (Figure $2 \mathrm{~b}$ ). Interestingly, neither SFK activities (Figure 2b and Supplementary Figure 1) nor cellular transforming abilities (Figure 2c) were significantly modified in cells with reduced Csk. It should be noticed a small ( 0.3 fold), but statistically significant elevation in SFK activities (Figure 2b and Supplementary Figure 1) and cellular invasion (Figure 2c) of SW480 and HCT116 cells, suggesting the existence of residual SFK coupling to Csk in early CRC. In contrast, a 50\% reduction of the Csk level was sufficient to increase SFK activities by 3-4 folds in MCF7 and ZR75.1 cells (Figure 2b and Supplementary Figure 1). Moreover, it induced an increase of neoplastic activities of those cells, i.e. anchorage-independent cell growth (3 fold) and invasion (10-20 fold) (Figure 2c), indicating that Csk is active in $\mathrm{ER}^{+}$breast cancer cells. We next confirmed this data with a pharmacological approach using the small molecule Csk inhibitor ASN2324598 (Kunte et al., 2005). This compound reduced the capacity of Csk to phosphorylate SFK both in an enzymatic assay and in cells, as illustrated with the example of MCF7 treated cells (Supplementary Figure 2). At the functional level, ASN234598 significantly increased both anchorage-independent growth and invasion of MCF7 cells, while having no effect on Colo205 cells (Supplementary Figure 2). We therefore concluded that Csk is essentially uncoupled from SFK activities in CRC cells, in contrast to breast cancer cells.

\section{A membrane-localised Csk re-regulates SFK invasive activity in CRC cells.}

We next asked whether Csk inhibition could be due to membrane mis-localisation. To address this question, Csk was fused to the Fyn [1-63] with both a myristilation and palmitoylation site (palm-Csk). Unlike wild-type Csk, this sequence allows Csk protein membrane targeting, and more specifically in cholesterol-enriched or rafts domains where a pool of SFK reside (Resh, 1999) (Figure 3a). As a consequence, palm-Csk reduced SFK 
activities of SW620 cells by about 50\%, unlike Csk (Figure 3b). This data was next confirmed by confocal immunofluorescence microscopy. Figure 3e shows global cytoplasmic Csk localisation, both at the overexpressed and the endogenous protein level. Some membrane staining could be detected in wild-type Csk over-expressing cells which however does not affect SFK activities. In contrast, cells expressing palm-Csk show strong membrane localisation leading to significant decrease in SFK activities. Moreover, active SFK were reduced when translocating Csk to the membranes in agreement with biochemical results. The effect of rafts-localised Csk was next assessed on SFK oncogenic signalling. We found that, unlike Csk, palm-Csk strongly inhibited cellular invasiveness (Figure 3d). However, the palm-Csk fusion protein did not affect cell growth (Figure 3c), indicating that the pool of SFK thus targeted was not involved in proliferation. We concluded that the Csk targeting to the membrane is sufficient to allow regulation of SFK invasive activity in CRC cells. Surprisingly, expression of wild-type Csk significantly increased the growth of SW620 cells in soft agar conditions (Figure 3c). The reason for this is currently unknown but it suggests that Csk could have a positive function, perhaps independent of SFK in some circumstances to be identified.

\section{Csk uncoupling is associated with down-regulation of PAG in CRC.}

We next searched for Csk-binding proteins involved in uncoupling of Csk. Since palm-Csk was concentrated in lipid rafts (Figure 3a), we hypothesised that the transmembrane protein PAG could be a likely candidate. Accordingly, a reduction in PAG protein level was observed in lipid rafts purified from late-stage CRC cells (Figure 4a). Strikingly, protein expression was completely lost in metastatic Colo205 cells. This PAG expression pattern was next confirmed in tumour biopsies obtained from patients with CRC relative to their respective non-transformed adjacent tissue. The level of the PAG transcript was strongly 
reduced in most neoplastic tissues examined (8/10) (Figure 4b). PAG inhibition was also confirmed at the protein level using immunofluorescent staining from normal and transformed colorectal tissues. PAG specific immunostaining was reduced in these tumour tissues, unlike that of Csk (Figure 4c). Similar results were obtained with an antibody specific to the PAG Cterminus confirming the specificity of PAG down-regulation (not shown). We thus concluded that PAG expression is inhibited in CRC.

We next analysed the biological consequence of PAG down-regulation. Firstly, we reintroduced PAG in cells derived from advanced CRC harbouring a low to undetectable level of endogenous PAG protein. We found that de novo expression of this transmembrane protein significantly increased Csk membrane localisation and reduced SFK activities (Figures 3e, Figures $5 \mathrm{a}$ and $\mathrm{b})$. At the functional level, PAG mimicked the effects of palm-Csk, i.e. a reduction of cell invasiveness, with no effect on soft agar cell growth (Figure 5c). Whether this PAG activity was mediated by Csk was next addressed. We found that PAG-regulated effects were counteracted by Csk inhibition. Specifically, treatment of PAG-expressing cells with ASN2324598 or transduction of shRNAs that specifically target Csk largely restored SFK kinase activity (Figures 5d and e) and cell invasion (Figure 5f). Lastly, residual PAG expression was knocked-down in cells derived from early CRC using a shRNA strategy (Figure 6a). We found that its inactivation induced a significant decrease in Csk membrane localisation (Figure 6b) and a remarkable increase in SFK activities (Figure 6a and Supplementary Figure 3). Again, while PAG down-regulation did not affect anchorageindependent growth of these cells (Figure 6c), it strongly increased their cellular invasiveness (Figure 6d). Similar results were obtained with a distinct shRNA sequence that also targets PAG (Supplementary Figure 3). Finally, we also observed that this increased cellular response was neutralised by the SFK inhibitor SU6656 (Figure 6d). Therefore, we concluded that PAG is implicated in Csk inactivation controlling SFK invasive activity of CRC cells. 


\section{DISCUSSION}

Although SFK have been largely implicated in CRC, the source of their oncogenic activity in this cancer is only partially understood. Here, we bring novel insights into the mechanisms involved. While protein overexpression clearly provides part of the response (Yeatman, 2004), additional mechanisms are expected to de-repress their catalytic activity. Accordingly, we show that mis-localisation of the negative regulator Csk is one important means for increased invasion of cancer cells via deregulated SFK activity. Indeed, Csk inactivation renders SFK overexpression sufficient to induce a deregulated form of the kinase, with oncogenic properties. This mechanism may particularly operate in advanced CRC cells, where tumour cells harbour maximal Csk membrane delocalisation together with a high SFK level. In this respect, a moderate expression of wild-type Src in advanced CRC SW620 cells is sufficient to increase oncogenic properties, in particular pro-invasive activity (Leroy et al., 2009). This may explain why CRC cells can withstand high Csk levels as observed in tumour biopsies. Whether this mechanism is specific to CRC is currently not known, but our data indicate that it may not operate in breast cancer, where Csk was still coupled to SFK. Alternative strategies may thus be used by these cells to overcome Csk-mediated inhibition, including SFK increased protein stabilisation (Tan et al., 2005) and the interaction with growth factor or hormonal receptors. It will however be important to address whether a similar mechanism operates in additional cancers where SFK are found to be deregulated.

A second feature of SFK oncogenic activity arising from our results is the existence of distinct pools of SFK controlling various aspects of cellular transformation. This notion is emphasised by the fact that rafts-targeted Csk re-regulates SFK invasive activity without affecting its growth promoting function. Moreover, Csk re-localisation to these membranes induced, at most, a 50\% reduction of SFK activity, confirming that it does not target all pools 
of SFK present in these cells. Accordingly, spatial regulation has been considered as an important feature of signal specificity induced by SFK in non-transformed cells (Veracini et al., 2006; Veracini et al., 2008) and this may apply for transformed cells as well. For example, when localised at focal adhesions, SFK play important roles in cell growth and survival (Frame, 2004). This pool of SFK may not be regulated by a membrane localised-Csk, but rather by a fraction of Csk present at focal adhesion in a complex with paxillin or Fak. An important issue related to this notion is the nature of the pool of SFK targeted by palm-Csk. Since this fusion protein is concentrated in lipid rafts, we believe that it targets the pool of SFK present in these domains. Lipid rafts have been proposed to be important regulators of SFK transforming activity (Collin et al., 2007; Oneyama et al., 2008). Nevertheless, their roles in CRC cells are ill-defined. A function for them has been assigned to the regulation of cell-cell adhesion, including adherent and tight junctions in epithelial cells (Causeret et al., 2005; Nusrat et al., 2000). Therefore, Csk inhibition may increase the effects of SFK oncogenic activity on cell dissociation and migration, processes involved in the epithelial to mesenchyme transition and required for cell dissemination and metastasis (Frame, 2004). However, SFK also control invasion of advanced CRC cells such as SW620, that have lost adherent junctions and this process is still inhibited when targeting Csk to the lipid rafts. Therefore, a yet to be identified, additional pool of SFK present in lipid rafts may promote cellular invasion.

We have also identified PAG down-regulation as an important mechanism of Csk inactivation in CRC cells. PAG belongs to the Transmembrane Adaptor Proteins (TRAP), the founder being the Linker of Activation of T cells (LAT), and it is ubiquitously expressed unlike other members of the TRAP family (Horejsi et al., 2004). PAG was originally identified as a Csk-binder implicating posphorylation of Tyr317 on PAG, but it contains 8 additional SFK phosphorylation sites allowing interaction with SH2-containing proteins, 2 
poly-Pro motifs for interaction with SH3-containing proteins and two palmitoylation sites implicated in lipid rafts localisation (Horejsi et al., 2004). Known interactors include the E3ligase SOCS1 (Ingley et al., 2006), the negative Ras regulator RasGAP (Smida et al., 2007) and SFK themselves (Oneyama et al., 2008; Solheim et al., 2008; Tauzin et al., 2008). Besides, we recently reported an unanticipated interaction between PAG N-terminus and the Neu-3 sialidase (Veracini et al., 2008), controlling lipid rafts properties (Miyagi et al., 2008). This data would predict that PAG could have diverse functions during oncogenesis. Accordingly, a negative function has recently reported in CRC tumour growth following xenotransplantation into immunodeficient mouse (Oneyama et al., 2008), but the underlying mechanism has not been addressed. Moreover, by sequestering SFK in lipid rafts, PAG inhibits Src transforming activity in mouse fibroblasts (Oneyama et al., 2008) but promotes Lyn oncogenic activity in B lymphoma (Tauzin et al., 2008). In both cases, PAG effects were independent of Csk. In contrast, our data clearly indicate that PAG negative function implicates Csk activity in CRC cells which is more relevant to colon cancer cell biology, since the previous studies used Csk-/- mouse embryonic fibroblasts as their model for cell transformation. An additional difference may rely on the high level of expressed PAG in fibroblasts that forces the segregation of Src in rafts, a situation that was not observed in CRC cells (see Figure 4a). Nevertheless, our study does not exclude additional Csk-independent function of PAG in CRC cells. How PAG is inactivated in CRC is another important issue that was partially addressed in this report. PAG expression is frequently inhibited in CRC (Oneyama et al., 2008 and this report), confirming the importance of this mechanism for SFK deregulation. Nevertheless, PAG is present in cells of early CRC, surmising additional mechanisms for signalling inhibition. Accordingly, one mechanism might implicate tyrosine phosphatases that dephosphorylate Csk binding sites, as reported with SHP2 during growth factor receptor signalling in non transformed cells (Zhang et al., 2004). 
Finally, our results may have significant implications in oncogenesis and cancer therapy. They first indicate that inhibition of a Csk-binding protein can be an important means to activation of SFK oncogenic signalling. In this respect, it will be important to analyse the role of additional Csk-binding proteins in CRC cancer. It also uncovers a novel strategy used by cancer cells to induce oncogenic activity of a proto-oncogene in the absence of a genetic mechanism, implicating a mis-localisation of its negative regulators. While not experimentally verified, this could also apply to signalling proteins such as small GTPases of the Ras or Rho family. Finally, since several small SFK inhibitors are under clinical trials in human cancer, several of them may affect Csk activity as well, thus lowering their efficacy towards SFK in tumourigenic tissues. While our data predict that this may not affect their activity in CRC, where Csk is inactive, it will be essential to determine their effects on Csk activity in other cancers, such as breast cancer. Finally, while very active in vitro, these inhibitors may not target all pools of SFK, including the ones present lipid rafts, due to the lipophilic micro-environment. It will therefore be important to design inhibitors that will also target this pool of SFK in advanced CRC tumours. 


\section{MATERIALS AND METHODS}

Reagents. SU6656 was from Calbiochem (La Jolla, CA) and ASN2324598 from Asinex (Moscow, Russia). [ $\gamma^{32}$ P]ATP was purchased from Amersham, poly-Glu-Tyr and Enolase from Sigma Aldrich (St Quentin, France). Purified FynK298M (FynK') was described in (Koegl et al., 1994). Anti-SFK (cst1) was described in (Veracini et al., 2006); anti-Src specific (2.17) antibody was a generous gift of Dr S. Parsons (University of Virginia, VA, USA). Anti-Csk was described in (Bénistant et al., 2001), anti-PAG in (Veracini et al., 2008). and anti-Cbp in (Oneyama et al., 2008). Polyclonal anti-Src[pY $\left.{ }^{418}\right]$ and anti-Src[pY $\left.{ }^{530}\right]$ specific antibodies were obtained from Biosource, anti-flotillin-1 and anti-pan-caveolin from BD-BioScience and anti-Transferrin Receptor (TR) from Zimed. Alexa Fluor 488 dye conjugated goat anti-Mouse or goat anti-rabbit and Alexa Fluor 594 dye conjugated goat antiMouse or goat anti-rabbit were from Alexa. Anti-phosphotyrosine 4G10 and anti-atubulin were a gift from P. Mangeat and N. Morin respectively (CRBM, Montpellier). Csk (Veracini et al., 2008), palm-Csk (Fyn[1-63]-Csk) have been cloned into pBABE retroviral vector. pRETRO-SUPER expressing shRNA Csk ${ }_{1562}$ (shRNA Csk 1), Csk ${ }_{340}$ (shRNA Csk 2) were from TRANSAT (Saint-Priest, France). A pRETRO-SUPER universal scramble with the following shRNA sequence GACACTCGGTAGTCTATAC (control) and shRNA luciferase (Luc) (Clonetech) were used negative controls as indicated. shRNA PAG 189

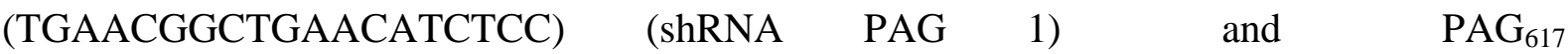
(TCTTTCGAGGCAGAAGTAG) (shRNA PAG 2) sequences targeting human PAG were cloned into pSIREN-retroQ as manufactured instructions (Clonetech). A construct expressing a shRNA Luc directed against the unrelated human Luciferase was used as a negative control (Clonetech). peFBOS encoding human PAG (Veracini et al., 2008) has been sub-cloned into pBABE retroviral vector. 
Cell culture and retro-viral infections. Cell lines (ATCC, Rockville, MD) were cultured as described previously (Sirvent et al., 2007) in specific growth medium (Invitrogen) supplemented with 10\% FCS: RPMI for SW620, SW480, HCT116, HT29, Colo205 and MCF7, DMEM F-12 for MDAMB231, MDAMB468, ZR75.1 and SKBR3. For drug treatments, cells were treated with the indicated inhibitor (or DMSO as a vehicle) for $24 \mathrm{~h}$ as indicated, in growth medium supplemented with 1\% FCS. Retroviral infections were performed as in (Sirvent et al., 2007) and stable-cell-lines have been obtained in a polyclonal background by puromycin $(1 \mu \mathrm{g} / \mathrm{ml})$ selection.

Anchorage independent cell growth, migration and invasion assays. For anchorageindependent cell growth, $0.67 \%$ agar in medium was layered on the bottom of a 12 wells plate and 1000 (CRC cells) or 4000 (MCF7 and ZR75.1) cells/well were seeded on the top of this layer in $0.33 \%$ agar-medium. After $18-21$ days colonies having $>50$ cells were scored positive. Inhibitors or vehicle (DMSO) were added every 3 days. Cell migration and invasion assays were performed in Boyden chambers (BD Bioscience) using 50,000 (CRC cells) and 150,000 cells (MCF7 and ZR75.1), for respectively 24h or 48h, and in the presence of $100 \mu \mathrm{l}$ of Matrigel (1.5 mg/ml) (BD Bioscience) for invasion assays.

\section{Human tissues collection, Immunofluorescent-staining, Microdissection and Q-PCR} analysis. Specimens of colon tumours (10 patients) and histologically normal epithelium were obtained from the pathologist according to governmental local ethic committee regulations (Nîmes hospital, France). Tissue sections, microdissection and RNA preparation were performed as previously described (Pannequin et al., 2007). Immunofluorescent staining was done as in (Pannequin et al., 2007) using 1/50 (PAG) to 1/200 (Csk) dilutions of previously described antibodies. Real-time quantitative PCR analyses were performed using the LightCycler Technology (Roche Diagnostic) as previously described (Boureux et al., 2005). 
Transcript levels were normalized to 36B4 mRNA levels. Primers used were as follows: PAG forward 5'-CAGTGGATACCATGCTCACG-3' and reverse 5'AGATTTTGCCTTGCCACTGT-3’; 36B4 forward 5’CATGCTCAACATCTCССССТTCTCC-3' GGGAAGGTGTAATCCGTCTCCACA-3’.

Biochemistry. Cell lysate, immunoprecipitation, Western-blotting and in vitro kinase assays for SFK and CSK were preformed as described in (Boureux et al., 2005). Protein expression and phosphorylation were quantified using ImageQuant TL software (Molecular Dynamics), and adjusted for background noise and protein loading. For membrane/cytoplasm fractionations, $10^{6}$ cells in a $60 \mathrm{~mm}$ plate, were lysed in hypotonic buffer $(10 \mathrm{mM}$ Tris-Hcl pH 7,5; $5 \mathrm{mM} \mathrm{MgCl} 2 ; 1 \mathrm{mM} \mathrm{DTT;} 1 \mathrm{mM}$ PMSF), subjected to Dounce homogeniser with 10 strokes and then centrifuged at $600 \mathrm{~g}$ for $5 \mathrm{~min}$ to remove nuclei and large cellular debris. Soluble proteins and plasmic membrane fractions (pellets) were separated by centrifugation at $100000 \mathrm{~g}$ for 45 minutes. Lipid rafts fractionations were done as described in (Veracini et al., 2008).

Immunostaining. Immunostaining was performed as described in (Collin et al., 2007). Briefly, cells were fixed 10 min with 3.7\% paraformaldehyde and permeabilized 3 min with $0.2 \%$ Triton in PBS. They were next incubated for $1 \mathrm{~h}$ with anti-Csk followed by anti-RabbitFITC (Sigma), anti-phospho-Src (Tyr418) clone 9A6 (Millipore) followed by anti-mouse Alexa-594 (Molecular Probes). Confocal images were acquired sequentially on a LSM 510 Meta Zeiss microscope, equipped with a 63X Apo W 1,2 N/A objective, using Ar 488-nm and He/Ne 543-nm excitation lasers. Fluorescein isothiocyanate and Alexa-594 channels were acquired using BP 505/530 and LP 560 emission filters, respectively. Image processing and analysis were performed on Image $\mathrm{J}$. 
Disclosure of Potential Conflicts of Interest

No potential conflicts of interest were disclosed. 


\section{ACKNOWLEDGEMENTS}

We thank M. Okada, S. Parsons, P. Mangeat and N. Morin for various reagents, C. Naudin, G. Collin and C. Leroy for technical assistance, Sylvain De Rossi and Virginie Georget (Montpellier RIO Imaging platform) for confocal microscopy analysis and J. Hickmann for helpful discussion. This work was supported by Servier Laboratories, la Ligue Nationale Contre le Cancer, CNRS, University of Montpellier 1 and 2 and l'Association pour la Recherche contre le Cancer (ARC, $n^{\circ}$ 4025). AS was supported by Servier Laboratories and by INCa. SR and CB are INSERM investigators. 


\section{REFERENCES}

Baumeister U, Funke R, Ebnet K, Vorschmitt H, Koch S, Vestweber D (2005). Association of Csk to VE-cadherin and inhibition of cell proliferation. Embo J 24: 1686-95.

Bénistant C, Bourgaux J, Chapuis H, Mottet N, Roche S, Bali J (2001). The C-terminal Src kinase is a tumour antigen in human carcinoma. Cancer Res 61: 1415-1420.

Boggon TJ, Eck MJ (2004). Structure and regulation of Src family kinases. Oncogene 23: 7918-27.

Boureux A, Furstoss O, Simon V, Roche S (2005). c-Abl tyrosine kinase regulates a Rac/JNK and a Rac/Nox pathway for DNA synthesis and c-myc expression induced by growth factors. J. Cell Sci 118: 3717-3726.

Brdicka T, Pavlistova D, Leo A, Bruyns E, Korinek V, Angelisova P et al (2000). Phosphoprotein associated with glycosphingolipid-enriched microdomains (PAG), a novel ubiquitously expressed transmembrane adaptor protein, binds the protein tyrosine kinase csk and is involved in regulation of T cell activation. $J$ Exp Med 191: 1591-604.

Cam WR, Masaki T, Shiratori Y, Kato N, Ikenoue T, Okamoto M et al (2001). Reduced Cterminal Src kinase activity is correlated inversely with pp60(c-src) activity in colorectal carcinoma. Cancer 92: 61-70.

Causeret M, Taulet N, Comunale F, Favard C, Gauthier-Rouviere C (2005). N-cadherin association with lipid rafts regulates its dynamic assembly at cell-cell junctions in C2C12 myoblasts. Mol Biol Cell 16: 2168-80.

Collin G, Franco M, Simon V, Benistant C, Roche S (2007). The Tom1L1-clathrin heavy chain complex regulates membrane partitioning of the tyrosine kinase Src required for mitogenic and transforming activities. Mol Cell Biol 27: 7631-40.

Emaduddin M, Bicknell DC, Bodmer WF, Feller SM (2008). Cell growth, global phosphotyrosine elevation, and c-Met phosphorylation through Src family kinases in colorectal cancer cells. Proc Natl Acad Sci U S A 105: 2358-62.

Frame MC (2004). Newest findings on the oldest oncogene; how activated src does it. $J$ Cell Sci 117: 989-98.

Horejsi V, Zhang W, Schraven B (2004). Transmembrane adaptor proteins: organizers of immunoreceptor signalling. Nat Rev Immunol 4: 603-16.

Imamoto A, Soriano P (1993). Disruption of the csk gene, encoding a negative regulator of Src family tyrosine kinases, leads to neural tube defects and embryonic lethality in mice. Cell 73: $1117-24$. 
Ingley E, Schneider JR, Payne CJ, McCarthy DJ, Harder KW, Hibbs ML et al (2006). Cskbinding protein mediates sequential enzymatic down-regulation and degradation of Lyn in erythropoietin-stimulated cells. J Biol Chem 281: 31920-9.

Irby RB, Mao W, Coppola D, Kang J, Loubeau JM, Trudeau W et al (1999). Activating SRC mutation in a subset of advanced human colon cancers. Nat Genet 21: 187-90.

Ishizawar RC, Tice DA, Karaoli T, Parsons SJ (2004). The C terminus of c-Src inhibits breast tumor cell growth by a kinase-independent mechanism. J Biol Chem 279: 23773-81.

Kawabuchi M, Satomi Y, Takao T, Shimonishi Y, Nada S, Nagai K et al (2000). Transmembrane phosphoprotein Cbp regulates the activities of Src-family tyrosine kinases. Nature 404: 999-1003.

Koegl M, Kypta RM, Bergman M, Alitalo K, Courtneidge SA (1994). Rapid and efficient purification of Src homology 2 domain-containing proteins: Fyn, Csk and phosphatidylinositol 3-kinase p85. Biochem J 302: 737-44.

Kunte DP, Wali RK, Koetsier JL, Hart J, Kostjukova MN, Kilimnik AY et al (2005). Downregulation of the tumor suppressor gene C-terminal Src kinase: an early event during premalignant colonic epithelial hyperproliferation. FEBS Lett 579: 3497-502.

Lee H, Volonte D, Galbiati F, Iyengar P, Lublin DM, Bregman DB et al (2000). Constitutive and growth factor-regulated phosphorylation of caveolin-1 occurs at the same site (Tyr-14) in vivo: identification of a c-Src/Cav-1/Grb7 signaling cassette. Mol Endocrinol 14: 1750-75.

Leroy C, Fialin, C, Sirvent, A, Simon, V, Urbach, S, Poncet, J et al (2009). Quantitative phosphoproteomics reveals a cluster of tyrosine kinases that mediates Src invasive activity in advanced colon carcinoma cells. Cancer Res in the press.

Liang F, Liang J, Wang WQ, Sun JP, Udho E, Zhang ZY (2007). PRL3 promotes cell invasion and proliferation by down-regulation of Csk leading to Src activation. $J$ Biol Chem 282: 5413-9.

Mao W, Irby R, Coppola D, Fu L, Wloch M, Turner J et al (1997). Activation of c-Src by receptor tyrosine kinases in human colon cancer cells with high metastatic potential. Oncogene 15: 3083-90.

Miyagi T, Wada T, Yamaguchi K (2008). Roles of plasma membrane-associated sialidase NEU3 in human cancers. Biochim Biophys Acta 1780: 532-7.

Nada S, Yagi T, Takeda H, Tokunaga T, Nakagawa H, Ikawa Y et al (1993). Constitutive activation of Src family kinases in mouse embryos that lack Csk. Cell 73: 1125-35.

Nusrat A, Parkos CA, Verkade P, Foley CS, Liang TW, Innis-Whitehouse W et al (2000). Tight junctions are membrane microdomains. J Cell Sci $113: 1771-81$.

Oneyama C, Hikita T, Enya K, Dobenecker MW, Saito K, Nada S et al (2008). The lipid raftanchored adaptor protein Cbp controls the oncogenic potential of c-Src. Mol Cell 30: 426-36. 
Pannequin J, Delaunay N, Buchert M, Surrel F, Bourgaux JF, Ryan J et al (2007). Betacatenin/Tcf-4 inhibition after progastrin targeting reduces growth and drives differentiation of intestinal tumors. Gastroenterology 133: 1554-68.

Read RD, Bach EA, Cagan RL (2004). Drosophila C-terminal Src kinase negatively regulates organ growth and cell proliferation through inhibition of the Src, Jun N-terminal kinase, and STAT pathways. Mol Cell Biol 24: 6676-89.

Resh MD (1999). Fatty acylation of proteins: new insights into membrane targeting of myristoylated and palmitoylated proteins. Biochim Biophys Acta 1451: 1-16.

Saito K, Enya K, Oneyama C, Hikita T, Okada M (2008). Proteomic identification of ZO-1/2 as a novel scaffold for Src/Csk regulatory circuit. Biochem Biophys Res Commun 366: 96975.

Schaller MD, Parsons JT (1995). pp125FAK-dependent tyrosine phosphorylation of paxillin creates a high-affinity binding site for Crk. Mol Cell Biol 15: 2635-45.

Sirvent A, Boureux A, Simon V, Leroy C, Roche S (2007). The tyrosine kinase Abl is required for Src-transforming activity in mouse fibroblasts and human breast cancer cells. Oncogene 26: 7313-23.

Smida M, Posevitz-Fejfar A, Horejsi V, Schraven B, Lindquist JA (2007). A novel negative regulatory function of PAG: blocking Ras activation. Blood 110:596-615.

Solheim SA, Torgersen KM, Tasken K, Berge T (2008). Regulation of FynT function by dual domain docking on PAG/Cbp. J Biol Chem 283: 2773-83.

Stewart RA, Li DM, Huang H, Xu T (2003). A genetic screen for modifiers of the lats tumor suppressor gene identifies C-terminal Src kinase as a regulator of cell proliferation in Drosophila. Oncogene 22: 6436-44.

Summy JM, Gallick GE (2003). Src family kinases in tumor progression and metastasis. Cancer Metastasis Rev 22: 337-58.

Tan M, Li P, Klos KS, Lu J, Lan KH, Nagata Y et al (2005). ErbB2 promotes Src synthesis and stability: novel mechanisms of Src activation that confer breast cancer metastasis. Cancer Res 65: 1858-67.

Tauzin S, Ding H, Khatib K, Ahmad I, Burdevet D, van Echten-Deckert G et al (2008). Oncogenic association of the Cbp/PAG adaptor protein with the Lyn tyrosine kinase in human B-NHL rafts. Blood 111: 2310-20.

Thomas SM, Brugge JS (1997). Cellular functions regulated by Src family kinases. Annu Rev Cell Dev Biol 13: 513-609.

Veracini L, Franco M, Boureux A, Simon V, Roche S, Benistant C (2006). Two distinct pools of Src family tyrosine kinases regulate PDGF-induced DNA synthesis and actin dorsal ruffles. J Cell Sci 20: 2921-34. 
Veracini L, Simon V, Richard V, Schraven B, Horejsi V, Roche S et al (2008). The Cskbinding protein PAG regulates PDGF-induced Src mitogenic signaling via GM1. J Cell Biol 182: $603-14$.

Yeatman TJ (2004). A renaissance for SRC. Nat Rev Cancer 4: 470-80.

Zhang SQ, Yang W, Kontaridis MI, Bivona TG, Wen G, Araki T et al (2004). Shp2 regulates SRC family kinase activity and Ras/Erk activation by controlling Csk recruitment. Mol Cell 13: 341-55.

Zhao M, Janas JA, Niki M, Pandolfi PP, Van Aelst L (2006). Dok-1 independently attenuates Ras/mitogen-activated protein kinase and Src/c-myc pathways to inhibit platelet-derived growth factor-induced mitogenesis. Mol Cell Biol 26: 2479-89.

Zheng X, Resnick RJ, Shalloway D (2008). Apoptosis of estrogen-receptor negative breast cancer and colon cancer cell lines by PTP alpha and src RNAi. Int J Cancer 122: 1999-2007.

Zhu S, Bjorge JD, Cheng HC, Fujita DJ (2008). Decreased CHK protein levels are associated with Src activation in colon cancer cells. Oncogene 27: 2027-34.

Zhu S, Bjorge JD, Fujita DJ (2007). PTP1B contributes to the oncogenic properties of colon cancer cells through Src activation. Cancer Res 67: 10129-37. 


\section{FIGURE LEGENDS}

\section{Figure 1. Cytoplasmic localisation of Csk in CRC cells.}

(a), Csk expression correlates with SFK activities in CRC cells. Western blot analysis showing the levels of active SFK ( $\left.\mathrm{pY}_{418} \mathrm{Src}\right)$ and Src that have been immunoprecipitated from indicated cancer cell-lines. Levels of Csk and tubulin from indicated whole cell-lysates are also shown. (b), Csk catalytic activity purified from CRC cells. In vitro kinase activity of Csk that was immunopurified using Csk specific antibody from indicated cell-lyates using polyGlu-Tyr (black boxes) or kinase dead FynK298M (white boxes) as a substrate, as shown. Relative kinase activity is shown and has been quantified as described in Materials and Methods. The mean \pm SD (n=3) is shown. (c), Csk is predominantly localised in the cytoplasm of CRC cells, unlike in breast cancer cells. Western blot analysis showing the level of Csk and SFK in membrane (m) and cytosolic (c) fractions from indicated cells lines and obtained as described in Materials and Methods using indicated antibodies. The level of Transferrin Receptor (TR) is also shown and was used as a control of membrane fractions. Note that the distinct protein migration detected between fractions was attributed to the high lipid content present in membrane fractions.

\section{Figure 2. Csk inactivation does not affect SFK invasive activity in CRC cells.}

(a), Anchorage-independent growth (left) and invasive (right panel) activities of CRC and breast cancer cells are regulated by SFK. Left, statistical analysis of colonies number obtained from indicated cells grown in soft-agar conditions and treated with the SFK inhibitor SU6656 (5 $\mu \mathrm{M}$ ) or vehicle (DMSO) as shown. Right, Statistical analysis of the number of cells/field that have invaded through matrigel in Boyden chamber assays in the presence of indicated 
compounds. The mean \pm SD $(n>3)$ is shown. (b), the impact of Csk depletion from CRC and breast cancer cells on SFK activities. Top, Western blotting of immunoprecipitated Csk in indicated cell-lines that have been infected with retrovirus expressing control shRNA or shRNA Csk 1 as shown. The level of tubulin is also shown. Bottom, Western blot analysis showing the levels of immunoprecipitated active SFK ( $\left.\mathrm{pY}_{418} \mathrm{Src}\right)$ and SFK of indicated cancer cell-lines. The level of phosphorylated Enolase $\left({ }^{32} \mathrm{P}\right.$-Enolase) used as an in vitro kinase assay from SFK immunoprecipitates is also shown and was obtained as described in Materials and Methods. (c), Csk depletion does not affect neoplastic activity of CRC cells, unlike breast cancer cells. Statistical analysis of colonies number (left panel) obtained from indicated cells grown in soft-agar conditions and of the number of cells/field that have invaded through matrigel in Boyden chamber assays (right panel). The mean $\pm \operatorname{SD}(n>3)$ is shown.

\section{Figure 3. A membrane-targeted Csk re-regulates SFK invasive activity in CRC cells.}

(a), Lipid rafts localisation of membrane-targeted palm-Csk in SW620. Western blotting of the levels of Cskand tubulin in lipid rafts and soluble fractions obtained from cells infected with indicated virus as described in Materials and Methods. (b), palm-Csk reduces SFK activities in SW620 cells. Western blotting of the level of Csk and SFK as shown from cells infected with indicated virus. In vitro kinase activity and quantified activity relative to control

cells of immunopurified SFK ( ${ }^{32}$ P-Enolase) is also shown. (c), palm-Csk does not affect anchorage-independent growth. Statistical analysis of colonies numbers obtained from indicated cells grown in soft-agar conditions is shown. (d), palm-Csk inhibits cellular invasion. Statistical analysis of the number of cells/field that have invaded through matrigel in Boyden chamber assays in the presence or the absence of indicated compound. The mean \pm SD $(n>3)$ is shown. (e), SFK regulation by Csk membrane targeting in SW620 cells assessed by immunocytochemistry. Cells infected with wild-type (mock) or indicated retroviruses were 
seeded on coverslips, fixed and processed for immunofluorescence as described in the Materials and Methods section. Is shown a representative example of active SFK (anti$\mathrm{pY}_{418} \mathrm{Src}$ ) and Csk immunostaining as indicated and obtained by confocal analysis as described in the Materials and Methods section.

\section{Figure 4. The Csk-associated transmembrane protein PAG is down-regulated in CRC.}

(a), PAG level in CRC cells. Western blotting of the levels of PAG and SFK in lipid rafts (r) and soluble (s) fractions obtained from indicated cell-lysates as described in Materials and Methods. The level of lipid-rafts markers caveolin- 1 and flotillin-1 are also shown. Downregulation of PAG expression in CRC tumours at the transcript (b) and the protein level (c). Relative PAG mRNA level was measured by Q-PCR as described in Materials and Methods from the microdissected tumour $(\mathrm{T})$ or the adjacent healthy tissues $(\mathrm{H})$ as indicated and were normalised to $100 \%$ for each healthy tissue of the same patient. Patient number and TNM status is shown. The mean $\pm \mathrm{SD}(\mathrm{n}>3)$ is shown. ${ }^{*} P<0.01$ and $* * P<0.001$ using a student's $t$ test; (c), Representative anti-PAG, anti-Csk and DAPI immunofluorescence staining from indicated tissue samples of 2 patients with CRC.

Figure 5. PAG overexpression inhibits SFK invasive activity in advanced CRC cells in a Csk-dependent manner.

(a). SFK kinase inhibition by PAG overexpression. Top, Western blot analysis showing the level of PAG in indicated cells that have been infected with mock or PAG retrovirus, as shown. Bottom, Western blot analysis showing the levels of immunoprecipitated active SFK $\left(\mathrm{pY}_{418} \mathrm{Src}\right)$ and SFK of indicated cancer cell-lines. The level of phosphorylated Enolase $\left({ }^{32} \mathrm{P}-\right.$ Enolase) used as an in vitro kinase assay from SFK immunoprecipitates is also shown and was obtained as described in Materials and Methods. (b) Csk membrane relocalisation 
induced by PAG overexpression, An example (top panel) and the statistical analysis (bottom panel) of Csk levels in membrane (m) and cytosolic (c) fractions from indicated cells lines and obtained as described in Materials and Methods. The level of Transferrin Receptor (TR) is also shown. (c), PAG reduces invasive activity in advanced CRC cells, without affecting their capacity to grow in soft-agar conditions. Statistical analysis of colonies number obtained from indicated cells infected with shown virus (left) ; statistical analysis of the number of cells/field that have invaded through matrigel in Boyden chamber assays (right). The mean \pm SD ( $\mathrm{n}>3$ ) is shown. (d), PAG inhibits SFK activities in a Csk-dependent fashion. Top panels, Western blot analysis showing the levels of immunoprecipitated active SFK ( $\mathrm{pY}_{418} \mathrm{Src}$ ) of SW620 cells that have been infected with indicated viruses. The level of phosphorylated Enolase ( ${ }^{32} \mathrm{P}$-Enolase) used as an in vitro kinase assay from SFK immunoprecipitates is also shown and was obtained as described in Materials and Methods. Bottom panels, the levels of Csk, SFK and PAG are also shown from the corresponding whole cell-lysates. (e) Top panels, Western blot analysis showing the levels of immunoprecipitated active SFK ( $\mathrm{pY}_{418} \mathrm{Src}$ ) of SW620 cells that have treated or not with ASN2324598 $(10 \mu \mathrm{M})$. The level of phosphorylated Enolase ( ${ }^{32} \mathrm{P}$-Enolase) used as an in vitro kinase assay from SFK immunoprecipitates is also shown and was obtained as described in Materials and Methods. Bottom panels, is shown the level SFK from the corresponding whole cell-lysates. (f), PAG reduces SFK invasive activity in a Csk-dependent fashion. Statistical analysis of the number of indicated cells/field that have invaded through matrigel in Boyden chamber assays in the presence or the absence of indicated ASN2324598 $(10 \mu \mathrm{M})$. The mean \pm SD $(\mathrm{n}>3)$ is shown.

Figure 6. Inactivation of residual PAG expression promotes SFK invasive activity in CRC cells of early-stage tumours. 
(a), PAG depletion increases SFK activities in early CRC cells. Top, PAG, SFK and caveolin levels in rafts fractions purified from cells infected with indicated viruses, as described in Materials and Methods. Bottom, Western blot analysis showing the levels of immunoprecipitated active SFK ( $\mathrm{pY}_{418} \mathrm{Src}$ ) of indicated cells. The level of phosphorylated Enolase $\left({ }^{32} \mathrm{P}\right.$-Enolase) used as an in vitro kinase assay from SFK immunoprecipitates is also shown and was obtained as described in Materials and Methods. (b), PAG depletion reduces Csk membrane localisation. An example (top panel) and the statistical analysis (bottom panel) of Csk levels in membrane (m) and cytosolic (c) fractions from indicated cells lines and obtained as described in Materials and Methods. The level of Transferrin Receptor (TR) is also shown. (c), PAG depletion does not affect anchorage-independent cell growth of early CRC cells. Statistical analysis of colonies number obtained from indicated cells infected with shown virus. (d), PAG depletion increases invasive activity of early CRC cells. Statistical analysis of the number of cells/field that have invaded through matrigel in Boyden chamber assays. The mean $\pm \operatorname{SD}(n>3)$ is shown. 